\title{
Termination Rate Coefficients for Radical Homopolymerization of Methyl Methacrylate and Styrene at Low Conversion
}

\section{David R. Taylor, Kim Y. van Berkel, Majed M. Alghamdi, Gregory T. Russell}

Department of Chemistry, University of Canterbury, Private Bag 4800, Christchurch, New Zealand

Fax: (+64) 3364 2110; E-mail: greg.russell@ canterbury.ac.nz

Dedicated to Prof. Dr. Michael Buback on the occasion of his $65^{\text {th }}$ birthday

ABSTRACT: A comprehensive and systematic study of overall termination rate coefficients, $k_{\mathrm{t}}$, in low-conversion radical (homo)polymerization of methyl methacrylate and styrene is presented. Values of $k_{\mathrm{t}}$ were determined by gravimetric analysis of steady-state experiments, employing 2,2'-azoisobutyronitrile as initiator. The values delivered by this simple method were found to be in qualitative and quantitative agreement with those from more modern and sophisticated techniques for measuring $k_{\mathrm{t}}$. Accordingly, correlations for bulk, low-conversion $k_{\mathrm{t}}$ as a function of temperature are given for each monomer. The effects of initiator concentration, $c_{\mathrm{I}}$, and temperature on bulk $k_{\mathrm{t}}$ were studied in a controlled way for both monomers. Additionally, ethyl benzene was used as solvent in order to investigate rigorously the effect of monomer concentration, $c_{\mathrm{M}}$, on styrene $k_{\mathrm{t}}$. The trends found by these systematic studies were considered in the light of what is known about the chain-length dependence of 
termination. Styrene's behavior was always found to be qualitatively in accord with expectation, although the variations of $k_{\mathrm{t}}$ with $c_{\mathrm{I}}$ and $c_{\mathrm{M}}$ were not as strong as should be the case. However its activation energy, $15 \mathrm{~kJ} \cdot \mathrm{mol}^{-1}$, is shown to be almost perfectly in agreement with theory. Methyl methacrylate, on the other hand, is recalcitrant in that its overall $k_{\mathrm{t}}$ does not make manifest the chain-length dependent termination that has been directly measured by other techniques. Possible reasons for these discrepancies are discussed, as are reasons for the difference in values between $k_{\mathrm{t}}$ for the two monomers. On the latter topic it is concluded likely that the chain-length dependence of termination at short chain lengths is primarily responsible for styrene having $k_{\mathrm{t}}$ that is higher by a factor of about 3 , with there also being a contribution that arises from styrene's slower propagation.

\section{Introduction}

In radical polymerization (RP) circles, for over a decade now the topic du jour has been reversible-deactivation RP (RDRP), vernacularly known as controlled/living RP. ${ }^{[1-3]}$ This might lead the uncritical observer to decide that conventional RP has become of only marginal relevance. Such a view would be mistaken. For a start there is the stark reality that still only a tiny fraction of commercial RP products are made by RDRP. Secondly, RDRP always has a conventional RP reaction scheme at its heart. This means, for example, that the propagation and termination reactions, rate coefficients $k_{\mathrm{p}}$ and $k_{\mathrm{t}}$ respectively, of conventional RP are also an intimate part of RDRP, exerting a pivotal role in their kinetics. ${ }^{[4,5]}$ Thirdly, far from spelling the end of it, the advent of RDRP has actually advanced the study of conventional RP kinetics, especially with regard to termination. ${ }^{[6]}$ 
In fact the last decade has actually witnessed an enormous amount of quiet but highly significant progress in the study of RP termination kinetics. ${ }^{[6]}$ Arguably the most important progress has come in the domain of measurement of chain-length-dependent termination (CLDT) rate coefficients. In this respect the work of Buback has been to the fore, with the proposal, development and successful exploitation of his methods of SP-PLP-EPR ${ }^{[7-11]}$ (single-pulse pulsed-laser polymerization coupled with EPR spectroscopy) and SP-PLPRAFT $^{[12-14]}$ (SP-PLP carried out with a reversible addition-fragmentation chain-transfer agent). These and in addition the RAFT-CLD-T ${ }^{[15,16]}$ method (steady-state use of RAFT polymerization to investigate CLDT) have enabled a picture of CLDT of unprecedented detail to emerge.

In particular, these methods have been successfully used to study the iconic monomers methyl methacrylate (MMA) $)^{[17-19]}$ and styrene (STY $)^{[15,16,20]}$ at low conversion of monomer into polymer. They have been found to conform to the so-called 'composite model' for CLDT, ${ }^{[21]}$ as indeed do virtually all systems studied so far. ${ }^{[6]}$ Notwithstanding this highly satisfactory congruence of theory and experiment, there can be found several motivations for using a simpler experimental method to study termination. These include: (1) Having evaluated the plethora of methods that there are for measuring $k_{\mathrm{t}}$, an IUPAC taskgroup concluded that all methods have their virtues, and that no method is unsound in principle. ${ }^{[22]}$ It is therefore of interest to see if a simple method can deliver results that concur with those of the more sophisticated methods mentioned above, and thus yield reliable data. (2) Even if a simple method delivers only the overall (chain-length averaged) $k_{\mathrm{t}}$, such values should vary in well predicted ways that reflect the underlying CLDT. ${ }^{[6,23,24]}$ Now that the details of CLDT are well established (see above), it is of interest to ascertain if $k_{\mathrm{t}}$ values do vary as would be expected. (3) While it is all good and well to measure $k_{\mathrm{t}}^{i, i}$, the rate coefficient for termination between radicals of chain length $i$, as in the state-of-the-art methods mentioned above, the 
fact remains that $k_{\mathrm{t}}$, as delivered by a more rustic method, is the quantity of technical importance. In addition to these considerations, there is the motivation of contributing to the building up of a comprehensive database of $k_{\mathrm{t}}$ values.

Given the above, an extensive series of measurements of steady-state $k_{\mathrm{t}}$ for MMA and STY at low conversion have been carried out in this work using gravimetry. Although this technique is the oldest and simplest in the book, ${ }^{[22]}$ its use remains remarkably widespread, especially with practitioners of RDRP, many of whom have backgrounds in synthetic chemistry that accustom them to measurement of yield in this way. The greatest advantage of this technique is obviously its simplicity, both conceptually and in terms of the instrumentation required. One major disadvantage is that the technique is labor intensive, especially if carried out scrupulously, as in this work, as now explained.

The major source of difficulty in using gravimetry is dissolved oxygen. Specifically, when removing a sample for gravimetric analysis, it is very difficult to exclude atmospheric oxygen from coming into contact with the polymerizing system. Thus sampling runs the risk of inducing retardation, which obviously is contrary to desire. The way around this is to separate samples prior to polymerization, and simply quench one sample at each measurement time. Such a procedure relies on the assumption that all samples start polymerizing at the same time, something one cannot be confident of if dissolved oxygen is present. Therefore it is necessary to rigorously exclude all oxygen from each sample, so that polymerization will immediately start in every case. In this work this was accomplished through freeze-pump-thawing of samples followed by immediate sealing of them. 


\section{Experimental Part}

Methyl methacrylate (MMA) was purified by distillation under reduced pressure. 2,2'Azoisobutyronitrile (AIBN) was recrystallized from ethanol at room temperature. Stock solutions of 0.01 wt. $\%, 0.1$ wt. $\%$ and 1.0 wt. $\%$ AIBN in MMA (where wt. $\%$ is AIBN relative to MMA plus AIBN) were prepared in sealed vials on the day of the experiment. Weighed samples of the stock solution (approx. $1.2 \mathrm{~mL}$ ) were placed in a number of Pyrex test tubes (approx. length $250 \mathrm{~mm}$, inner diameter $7 \mathrm{~mm}$ ). The samples in the tubes then underwent freeze-pump-thawing to remove all the oxygen, as follows.

Samples were frozen under an argon atmosphere using liquid nitrogen. A vacuum was applied for $90 \mathrm{~s}$ while the tubes remained submerged in the liquid $\mathrm{N}_{2}$. The tubes were then removed and allowed to thaw under vacuum for $30 \mathrm{~s}$, at which time the argon atmosphere was reintroduced (a most likely unnecessarily cautious measure to guard against a weak or leaky vacuum). Full thawing was then effected by placing the tubes in water at room temperature. This routine was repeated three times. On the last cycle the tubes were placed back in the liquid $\mathrm{N}_{2}$ after the initial phase of thawing. While the samples were frozen and under vacuum the tubes were sealed. This was done either by flame-sealing (leaving a tube of approx. 150 mm length) or, in later experiments, by closing an attached stopcock. The samples were then left to thaw at room temperature.

Each tube was then placed in a water bath at a set temperature for a different length of time. Following the prescribed period of polymerization, each tube was removed and placed in an ice bath to cool for approximately 20-30 s, depending on the polymerization temperature. The capsules were then opened (by breaking in the case of flame-sealing) and injected with a known quantity of a $10 \%$ solution of the inhibitor 2,6-di-tert-butylphenol, previously recrystallized from $n$-hexane, in THF. The sample was then transferred to a 
weighed aluminium tray, weighed, and placed in an oven (at approx. $60 \cdot \mathrm{C}$ ) to dry overnight. The pan containing the dried polymer was then weighed. In determining the conversion of monomer into polymer from these weights it was assumed that the drying process removes all monomer, initiator, inhibitor and THF.

Styrene (STY) experiments were carried out exactly as above, with the following additional details. Ethyl benzene (EB) was purified by distillation. Solutions of $100 \%, 80 \%$, $60 \%, 40 \%$ and $20 \%$ by volume (relative to total volume) of STY in EB were prepared and kept in sealed vials. It was assumed that the volume fraction as prepared at room temperature remained unchanged in heating to polymerization temperature. Stock solutions of AIBN concentration $5.5 \times 10^{-4} \mathrm{M}$ (equivalent to $1.0 \mathrm{wt}$. $\%$ in bulk experiments) in the various diluted STY solutions were prepared in sealed vials on the day of the experiment.

\section{Data Analysis and Results}

Typical conversion-time results are presented in Figure 1. The well-known increase of rate with initiator concentration is immediately evident. More worthy of comment are the results from duplicate experiments at 1.0 wt. \% AIBN. Even though the agreement between individual data points is reasonably close and looks to be within experimental scatter, the differences lead to $k_{\mathrm{t}}$ values (see below) of 3.0 and $2.4 \times 10^{7} \mathrm{~L} \cdot \mathrm{mol}^{-1} \cdot \mathrm{s}^{-1}$ in this case, i.e., about $20 \%$ difference. This is typical for $k_{\mathrm{t}}$ measurement in general, ${ }^{[25]}$ even with modern methods, and certainly suggests that gravimetry, when carried out properly, is no less precise than many other methods. This agreement is quite remarkable in the case of the Figure 1 results, because in fact one of the duplicate experiments was carried out without deoxygenation of samples. It is evident that this has not impaired the quality of the results, 
and in fact this experiment yielded the lower of the $k_{\mathrm{t}}$ values, which is contrary to the expectation that lingering $\mathrm{O}_{2}$ might lead to slight retardation (i.e., higher $k_{\mathrm{t}}$ ). This lack of effect can be attributed to the high temperature and the high initiator concentration, both of which will see $\mathrm{O}_{2}$ consumed quickly. However in general stringent measures should be taken to exclude oxygen in carrying out experiments like this.

To analyze data it has been recommended to use $\mathrm{e}^{[22]}$

$$
\frac{-\mathrm{d} \ln (1-x)}{\mathrm{d} t}=k_{\mathrm{p}} c_{\mathrm{R}}=k_{\mathrm{p}}\left(\frac{f k_{\mathrm{d}} c_{\mathrm{I}}}{k_{\mathrm{t}}}\right)^{0.5} \equiv k_{\mathrm{o}}
$$

Here $x$ is the fractional conversion of monomer into polymer, $t$ time, $c_{\mathrm{R}}$ the overall radical concentration, $k_{\mathrm{t}}, k_{\mathrm{p}}$ and $k_{\mathrm{d}}$ the rate coefficients for termination, propagation and initiator decomposition respectively, and $f$ and $c_{\mathrm{I}}$ initiator efficiency and concentration respectively. Equation (1) suggests plotting data as $-\ln (1-x)$ versus $t$, as has been done in Figure 1 . The derivation of Equation (1) assumes only a steady state in radical concentration and that there is negligible consumption of monomer by reactions other than propagation. ${ }^{[22]}$ Contrary to belief in some quarters, it is not assumed that any of the rate parameters must be constant in value. Variation with time of the overall rate parameter $k_{\mathrm{o}}$, defined as in Equation (1) and including $c_{\mathrm{I}}$, will manifest itself as curvature in a plot of $-\ln (1-x)$ versus $t$. In such an event $k_{\mathrm{o}}$ must be obtained as the tangent of the plot. However it is evident from Figure 1 that, as expected, our data is linear within experimental error. This was always the case, with experiments typically being carried out to up to $10-15 \%$ conversion. Thus our reported $k_{\mathrm{o}}$ values were always obtained as the slope of a linear fit of all $-\ln (1-x)$ versus $t$ data for a particular experiment. We report $k_{\mathrm{o}}$ rather than the more usual $k_{\mathrm{o}} /\left(c_{\mathrm{I}}\right)^{0.5}$ simply because the slope (i.e., $k_{\mathrm{o}}$ ) is the directly obtained experimental quantity.

From $k_{\mathrm{o}}$ the value of $k_{\mathrm{t}}$ is obtained using 


$$
k_{\mathrm{t}}=f k_{\mathrm{d}} c_{\mathrm{I}}\left(\frac{k_{\mathrm{p}}}{k_{\mathrm{o}}}\right)^{2}
$$

This makes clear that accuracy in $k_{\mathrm{t}}$ is dependent on accuracy in $k_{\mathrm{p}}$ and $f k_{\mathrm{d}}$. In this work we have used the following expressions:

$$
\begin{aligned}
& k_{\mathrm{p}}(\mathrm{MMA})=2.673 \times 10^{6} \mathrm{~L} \cdot \mathrm{mol} \cdot \mathrm{s}^{-1} \exp \left(\frac{-22.36 \mathrm{~kJ} \cdot \mathrm{mol}^{-1}}{R T}\right) \\
& k_{\mathrm{p}}(\mathrm{STY})=4.266 \times 10^{7} \mathrm{~L} \cdot \mathrm{mol} \cdot \mathrm{s}^{-1} \exp \left(\frac{-32.51 \mathrm{~kJ} \cdot \mathrm{mol}^{-1}}{R T}\right) \\
& f k_{\mathrm{d}}(\mathrm{AIBN} \text { in MMA })=1.017 \times 10^{14} \mathrm{~s}^{-1} \exp \left(\frac{-123.5 \mathrm{~kJ} \cdot \mathrm{mol}^{-1}}{R T}\right) \\
& f k_{\mathrm{d}}(\mathrm{AIBN} \text { in STY })=1.417 \times 10^{14} \mathrm{~s}^{-1} \exp \left(\frac{-123.5 \mathrm{~kJ} \cdot \mathrm{mol}^{-1}}{R T}\right)
\end{aligned}
$$

Equations (3a) and (3b) are IUPAC-recommended benchmark values. ${ }^{[26,27]}$ Equation (4b) is from re-expression ${ }^{[28]}$ of earlier measurements of $f k_{\mathrm{d}}$ for AIBN in bulk polymerization of STY at low conversion, ${ }^{[29]}$ i.e., exactly as in the experiments here. Equation (4a) is just Equation (4b) multiplied by 0.718 , this being the factor by which Fukuda et al. measured $f k_{\mathrm{d}}$ for AIBN to be smaller in MMA than in STY at $40 \cdot \mathrm{C} .{ }^{30}$ In the absence of more specific information about AIBN, it was assumed in this work that this variation is the same at all temperatures. However this assumption is unlikely to hold exactly, because the factors that cause $f$ and $k_{\mathrm{d}}$ to vary with solvent, ${ }^{[31,32]}$ for example viscosity and solvent nature, will vary differently with temperature according to the solvent (which in the present case is monomer).

Both $k_{\mathrm{o}}$ and $k_{\mathrm{t}}$ values are reported in the tables of experimental results. This will enable easy reprocessing of the assumption-free experimental quantity of $k_{\mathrm{o}}$ should more 
accurate parameter values for use in Equation (2) subsequently become available. Also given in the tables are values of $D P_{\mathrm{n}}$, the number-average degree of polymerization, calculated via the well-known equation ${ }^{[33]}$

$$
\frac{1}{D P_{\mathrm{n}}}=C_{\mathrm{trM}}+\frac{(1+\lambda)\left(f k_{\mathrm{d}} c_{\mathrm{I}} k_{\mathrm{t}}\right)^{0.5}}{k_{\mathrm{p}} c_{\mathrm{M}}}
$$

For the constant for chain transfer to monomer we used the following expressions from Stickler $^{[34]}$ and from Tobolsky and Offenbach ${ }^{[35]}$ respectively:

$$
\begin{aligned}
& C_{\mathrm{trM}}(\mathrm{MMA})=7.413 \times 10^{-2} \exp \left(\frac{-23.74 \mathrm{~kJ} \cdot \mathrm{mol}^{-1}}{R T}\right) \\
& C_{\mathrm{trM}}(\mathrm{STY})=2.2 \times 10^{-1} \exp \left(\frac{-23.4 \mathrm{~kJ} \cdot \mathrm{mol}^{-1}}{R T}\right)
\end{aligned}
$$

Despite the low-conversion (i.e., high- $k_{\mathrm{t}}$ ) conditions, the contributions of these values to calculated $D P_{\mathrm{n}}$ were not as negligible as one might anticipate, especially at $0.01 \mathrm{wt}$ \% AIBN; so it is not just out of completeness that chain transfer to monomer has been included. For the fraction of termination by disproportionation we used $\lambda=0.63$ for $\mathrm{MMA}^{[36]}$ and $\lambda=0.1$ for STY. ${ }^{[37]}$ Of course the value of $\lambda$ should vary with temperature, ${ }^{[37]}$ however there is no reliable information in the literature on this variation, ${ }^{[36,37]}$ and therefore we have simply used the given values at all temperatures. Finally, monomer concentration, $c_{\mathrm{M}}$, was calculated using the following expressions for specific volume, $V_{\mathrm{M}}$, of $\mathrm{MMA}^{[38]}$ and density, $d_{\mathrm{M}}$, of STY $^{[28,39]}$ respectively:

$$
\begin{aligned}
& V_{\mathrm{M}}(\mathrm{MMA}) /\left(\mathrm{cm}^{3} \cdot \mathrm{g}^{-1}\right)=1.025934+0.001494 \cdot \theta /{ }^{\circ} \mathrm{C} \\
& d_{\mathrm{M}}(\mathrm{STY}) /\left(\mathrm{g} \cdot \mathrm{cm}^{-3}\right)=0.92427-9.2004 \times 10^{-4} \cdot \theta /{ }^{\circ} \mathrm{C}
\end{aligned}
$$


No attempt was made to correct the resulting values of $c_{\mathrm{M}}$, which pertain to zero conversion, for the fact that a finite range of conversion was covered in experiments (see above). The reason for presenting calculated values of $D P_{\mathrm{n}}$ is that, because of chain-length-dependent termination, $k_{\mathrm{t}}$ is correlated with $D P_{\mathrm{n}}{ }^{[6,40]}$ In the absence of accompanying measurements of $D P_{\mathrm{n}}$, it seems advisable to at least give a best-possible estimate of this quantity for the experiments carried out.

Results are presented in Table 1 for MMA bulk polymerizations, Table 2 for STY bulk polymerizations and Table 3 for STY solution polymerizations.

\section{Discussion}

\section{Background}

The composite model for termination is ${ }^{[21]}$

$$
\begin{aligned}
& k_{\mathrm{t}}^{i, i}=k_{\mathrm{t}}^{1,1} i^{-\alpha_{\mathrm{S}}}, i \leq i_{\mathrm{c}} \\
& k_{\mathrm{t}}^{i, i}=k_{\mathrm{t}}^{1,1}\left(i_{\mathrm{c}}\right)^{-\alpha_{\mathrm{S}}+\alpha_{\mathrm{L}}} i^{-\alpha_{\mathrm{L}}}, i>i_{\mathrm{c}}
\end{aligned}
$$

This model has been found to describe the chain-length-dependent termination kinetics of MMA and STY, ${ }^{[6]}$ and values of the four model parameters have been tabulated for these (and other) monomers. ${ }^{[6]}$ Briefly, for MMA it has been found that $\alpha_{\mathrm{S}} \cdot 0.65,{ }^{[17-19]}$ this parameter giving the variation of $k_{\mathrm{t}}^{i, i}$ with $i$ for small ('S') chains. The crossover ('c') to long-chain behavior occurs at chain length $i_{\mathrm{c}} \cdot 100 .^{[17]}$ These values are very much in accord with theoretical expectations ${ }^{[21]}$ and with measurements of oligomer diffusion coefficients. ${ }^{[41]}$ For long (' $L$ ') chains there exists a wealth of data ${ }^{[6,17,24,42-46]}$ supporting the prediction of theory ${ }^{[47]}$ 
that $\alpha_{\mathrm{L}}=0.16$. All these values are essentially the same for other $n$-alkyl methacrylates, ${ }^{[6,9,11]}$ which strongly suggests a family-type behavior.

For STY the situation is largely the same, although admittedly the short-chain behavior is not as well studied experimentally: ${ }^{[6]} \alpha_{\mathrm{S}} \cdot 0.5$ and $i_{\mathrm{c}} \cdot 50,{ }^{[15,16,20]}$, again in accord with expectation, ${ }^{[21]}$ with oligomer diffusion coefficients, ${ }^{[48]}$ and with measurements on methacrylates with more spherical pendant groups; $;^{[9,11]}$ and $\alpha_{\mathrm{L}} \cdot 0.16,{ }^{[15,16,20,44-46,49]}$ as predicted by theory. ${ }^{[47]}$

While all this amounts to a highly pleasing chapter of scientific work, unfortunately it does not easily lead to prediction of the overall termination rate coefficient, $k_{\mathrm{t}}$, as measured in the present work, because Equation (8) cannot yield a closed expression for $k_{\mathrm{t}}{ }^{[21]}$ Fortunately this turns out not to matter. This is because even where the composite model holds, if $D P_{\mathrm{n}}>$ $i_{\mathrm{c}}$, as is the case in this work, then termination behavior is dictated by the long-chain portion of Equation (8). ${ }^{[6,21,40]}$ In other words, it is prescribed by

$$
k_{\mathrm{t}}^{i, i}=k_{\mathrm{t}}^{1,1} i^{-\alpha}
$$

where $\alpha$ is to be understood as $\alpha_{\mathrm{L}}$ and $k_{\mathrm{t}}^{1,1}$ is a diminished - see Equation (8) - value of the true $k_{\mathrm{t}}^{1,1}{ }^{[6]}$ Where Equation (9) holds, the following closed expression ${ }^{[6,21,45]}$ has been shown to give $k_{\mathrm{t}}$ values very well for steady-state RP, and in particular it is highly accurate in the trends it predicts: ${ }^{[24,50]}$

$$
k_{\mathrm{t}}=k_{\mathrm{t}}^{1,1}\left[\Gamma\left(\frac{2}{2-\alpha}\right)\right]^{-2}\left[\frac{\left(4 f k_{\mathrm{d}} c_{\mathrm{I}} k_{\mathrm{t}}^{1,1}\right)^{0.5}}{k_{\mathrm{p}} c_{\mathrm{M}}}\left(\frac{2}{2-\alpha}\right)\right]^{2 \alpha /(2-\alpha)}
$$

Here $\Gamma$ is the gamma function. The complexity of this equation stems from the fact that it is the appropriately weighted average of all the simultaneously operative $k_{\mathrm{t}}^{i, i}$ of a steady-state $\mathrm{RP}^{[6,21]}$ 
The measured $k_{\mathrm{t}}$ values of this work will now be examined in the light of Equation (10). It is therefore stressed that this equation is of proven pedigree.

\section{Variation of $k_{\mathrm{t}}$ with Initiator Concentration}

All else being equal, Equation (10) decrees that ${ }^{[6,23,24,50]}$

$$
k_{\mathrm{t}} \sim\left(c_{\mathrm{I}}\right)^{a}
$$

where

$$
a=\frac{\alpha}{2-\alpha} \Leftrightarrow \alpha=\frac{2 a}{1+a}
$$

The qualitative understanding here is that as $c_{\mathrm{I}}$ increases, average polymer size becomes smaller, which means that $k_{\mathrm{t}}$ becomes higher. ${ }^{[51]}$

Taking $\alpha=0.16$ (see the previous subsection), one arrives from above at the expectation that $k_{\mathrm{t}} \sim\left(c_{\mathrm{I}}\right)^{0.087}$. In order to test this prediction, in this work we were very careful to carry out various sets of experiments in which all else was equal: identical monomer concentration, temperature and initiator (see Tables 1 and 2). Literally the only variable from experiment to experiment in a particular set was AIBN concentration. Typical results for MMA and STY are presented in Figure 2. This is a case where the word 'typical' may be used with justification, because $\log -\log$ plots of $k_{\mathrm{t}}$ versus $c_{\mathrm{AIBN}}$ were obtained with slope $a=$ $-0.034\left(50{ }^{\circ} \mathrm{C}\right),-0.023\left(60{ }^{\circ} \mathrm{C}\right)$ and $-0.023\left(70{ }^{\circ} \mathrm{C}\right.$; see Figure 2$)$ for MMA, while our STY results deliver $a=+0.011\left(60{ }^{\circ} \mathrm{C}\right),+0.046\left(70{ }^{\circ} \mathrm{C}\right.$; see Figure 2$)$ and $+0.032\left(80^{\circ} \mathrm{C}\right)$. In other words, for a particular monomer the slope was virtually independent of temperature.

It is evident from these results that the expectation of $k_{\mathrm{t}} \sim\left(c_{\mathrm{I}}\right)^{0.087}$ is not nearly met. The result closest to this comes from STY at $70{ }^{\circ} \mathrm{C}$ (see Figure 2). Even there, $a=0.046$ gives $\alpha=0.09$ (see Equation (12)), which is a considerably weaker than expected chain-length 
dependence. Other sets of results have variations of $k_{\mathrm{t}}$ with $c_{\mathrm{I}}$ that are so weak that, were one not to know otherwise, one would conclude that termination is chain length independent $(\alpha=$ 0). In fact this was the conclusion that people did draw for many years, because historically it has commonly been found that $k_{\mathrm{t}}$ at low conversion for MMA and STY is essentially invariant with $c_{\mathrm{I}}{ }^{[51,52]}$ Indeed, textbooks generally bear such results. However now that it is so definitively established that $\alpha_{\mathrm{L}} \cdot 0.16$ for MMA and STY at low conversion, it cannot be concluded from measuring $a \bullet 0$ that termination is chain length independent. Rather, the question must become: why is $a \bullet 0.1$ not obtained in experiments of the present nature?

The first thing to say is that the apparent invariance of $k_{\mathrm{t}}$ with $c_{\mathrm{I}}$ cannot be due to errors in $k_{\mathrm{p}}$ or $f k_{\mathrm{d}}$ in determining $k_{\mathrm{t}}$ (see Equation (2)). While every effort has been made here to use highly accurate values of $k_{\mathrm{p}}$ and $f k_{\mathrm{d}}$, it is still possible that they contain appreciable error. However any such error will be constant across a set of experiments, because for each experiment in a set the values of $k_{\mathrm{p}}$ (for long chains) and $f k_{\mathrm{d}}$ must be exactly the same. Therefore errors in (long-chain) $k_{\mathrm{p}}$ and $f k_{\mathrm{d}}$ will not have any effect on obtained trends.

Next it is natural to look at the scatter in the points of Figure 2 and wonder whether random error is at work. However this too can be ruled out as the cause of the discrepancy, because random error would result in just as many determinations giving too high values of $a$. What really stands out is that values of $a$ are invariably too low. This is consistently the case both in this work (see the 6 values found here) and across most other works, as already mentioned.

Thus one is forced to consider systematic errors. A possibility is temperature variation with $c_{\mathrm{I}}$. Specifically, as $c_{\mathrm{I}}$ increases, rate increases, leading to a higher rate of heat evolution, which may lead to a slight rise in polymerization temperature. Since $k_{\mathrm{t}} \sim f k_{\mathrm{d}}\left(k_{\mathrm{p}}\right)^{2}$ (see Equation (2)), it follows that $k_{\mathrm{t}}$ will be underestimated if the temperature was actually slightly higher than the assumed value. In other words, the increase of $k_{\mathrm{t}}$ with $c_{\mathrm{I}}$ will be 
underestimated. While all this is plausible in principle, it is highly unlikely in practice, for two reasons: (1) STY and MMA polymerizations prior to the gel effect have relatively low rates of polymerization, meaning the rate of heat generation is relatively low; and (2) heat dissipation at low conversion is assisted by the highly fluid nature of these systems. Nevertheless, the possibility of temperature exotherms cannot be ruled out. It has been found that these occur in pulsed-laser polymerizations of $\mathrm{MMA},{ }^{[53]}$ although admittedly such systems are of higher rate than steady-state experiments. It is also noteworthy that MMA experiments have higher rate than STY experiments, meaning they should be more prone to exotherm effects. This is consistent with the finding both here (see $a$ values reported above) and in other works ${ }^{[52]}$ that MMA results deviate more from the expected non-classical behavior than do STY results.

Another possible explanation is the occurrence of chain transfer. Equation (10) is valid only in the absence of transfer. Where transfer occurs, the value of $a$ will be lower than predicted by Equation (10), and it will be zero (i.e., $k_{\mathrm{t}}$ invariant with $c_{\mathrm{I}}$ ) in the limit of all dead-chain formation being by transfer, regardless of the chain-length dependence of termination. ${ }^{[6,24]}$ This is consistent with the present experimental findings. However it would be a great surprise if transfer had occurred to a major extent in our experiments, and it would fly in the face of all received knowledge about low-conversion MMA and STY systems. As already mentioned in the previous section, our calculations of $D P_{\mathrm{n}}$ confirmed that transfer to monomer should have occurred only to a minor extent in our experiments.

Chain-length-dependent propagation ${ }^{[54]}$ (CLDP) also provides a rationalization for observing $a \bullet 0$. The logic is as follows: as $c_{\mathrm{I}}$ increases, $D P_{\mathrm{n}}$ decreases, meaning that CLDP could cause greater elevation of $k_{\mathrm{p}}$ from the long-chain value, as given by Equation (3). By assuming said long-chain values in data analysis, $k_{\mathrm{p}}$ is underestimated, meaning that $k_{\mathrm{t}}$ is underestimated, since $k_{\mathrm{t}} \sim\left(k_{\mathrm{p}}\right)^{2}{ }^{2}{ }^{[55]}$ Thus the true variation of $k_{\mathrm{t}}$ with $c_{\mathrm{I}}$ will be stronger than 
the deduced apparent one. For this explanation to hold with the present data requires that CLDP effects persist right through to relatively long polymer sizes. There is some evidence for this, ${ }^{[56,57]}$ and it certainly remains an open issue. However the bulk of the evidence suggests that CLDP is a small-chain phenomenon; ${ }^{[54]}$ consequently, for STY and MMA at least, CLDP is only expected to give noticeable increase of $k_{\mathrm{p}}$ where $D P_{\mathrm{n}}<100 .{ }^{[40]}$ This will not have been the case in this work (see the calculated values of Tables 1 and 2), which means that the above explanation for observing $a \bullet 0$ most likely runs aground.

Lastly, attention is drawn to a possible explanation put forward some time ago. ${ }^{[51]}$ It is based on the fact that the $k_{\mathrm{t}}$ measured in gravimetry experiments is actually an average over a range of conversion, in the present case about $0-10 \%$. While $k_{\mathrm{t}}$ is relatively constant over such low-conversion intervals for monomers like MMA and STY, in fact, for thermodynamic reasons, a slight increase in $k_{\mathrm{t}}$ takes place as polymer is formed, typically by about $20 \%{ }^{[58]}$ Further, the longer the chains, the stronger this effect. Thus at low $c_{\text {I }}$ this effect will be strongest, while at high $c_{\mathrm{I}}$ it will be weakest. This means there will be a canceling out of the zero-conversion variation of $k_{\mathrm{t}}$ with $c_{\mathrm{I}},{ }^{[51]}$ consistent with observation.

In the light of all the above, it is appropriate to mention a careful study of the present nature that was carried out by Stickler. ${ }^{[59]}$ Through employing a sophisticated dilatometric setup, he was able to measure MMA $k_{\mathrm{t}}$ with high precision over just the first $5 \%$ of conversion. The resulting data gives $k_{\mathrm{t}} \sim\left(c_{\mathrm{I}}\right)^{0.11}$, implying $\alpha=0.20 .^{[24]}$ This proves that steady-state rate data can yield $\alpha_{\mathrm{L}}$ values that are consistent with those from more modern and elaborate techniques. ${ }^{[6]}$ One thing that stands out about Stickler's experiments is the small range of conversion, which would reduce any effects from variation of $k_{\mathrm{t}}$ during the course of an experiment. Equally, his specially designed dilatometric procedure would likely have ensured efficient heat transfer, and thus the absence of any temperature exotherms. 


\section{Variation of $k_{\mathrm{t}}$ with Monomer Concentration}

All else being equal, Equation (10) pronounces that ${ }^{[6,23,24,50]}$

$$
k_{\mathrm{t}} \sim\left(c_{\mathrm{M}}\right)^{-2 a}
$$

where $a$ is as given by Equation (12). The physical understanding here is that as $c_{\mathrm{M}}$ decreases, chains grow more slowly, which means that radicals are smaller on average, which means that $k_{\mathrm{t}}$ is higher. ${ }^{[51]}$

Equation (13) suggests carrying out solution polymerizations in order to determine $\alpha$. The problem here is that it is difficult to vary $c_{\mathrm{M}}$ so that all else is equal. Specifically, solvent will have a different viscosity to monomer, and thus using different amounts of solvent will result in the viscosity varying. This means that $k_{\mathrm{t}}^{1,1}$ will change, providing a second avenue i.e., in addition to $c_{\mathrm{M}}$ - through which $k_{\mathrm{t}}$ is altered (see Equation (10)). Further, solvent power will also change, which has been shown to bring about change in $\alpha,{ }^{[60]}$ also affecting $k_{\mathrm{t}}$. Given all this, it is no surprise that there has been tremendous diversity in findings about the effect of (starting) $c_{\mathrm{M}}$ on solution polymerization $k_{\mathrm{t} .}{ }^{[51]}$

To address this situation we decided to carry out solution polymerizations of STY with ethyl benzene (EB) as solvent. Because EB is the saturated analogue of STY, replacement of monomer with solvent should result in negligible change of both viscosity and solvent power. Thus any variation of $k_{\mathrm{t}}$ should be due to change of $c_{\mathrm{M}}$ alone (where constant $c_{\mathrm{I}}$ and temperature are also elements of experimental design). Results are listed in Table 3 and

plotted in Figure 3. As is shown, $k_{\mathrm{t}} \sim\left(c_{\mathrm{M}}\right)^{-0.090}$ was found. This gives $a=0.045$ (Equation (13)), and hence $\alpha=0.09$ (Equation (12)). By contrast, the expectation from $\alpha=0.16$ is $k_{\mathrm{t}} \sim$ $\left(c_{\mathrm{M}}\right)^{-0.17}$

On the one hand it is pleasing that the results of Figure 3 evidence chain-lengthdependent termination, even if to a weaker than anticipated extent - this is at least an 
improvement on the results for variation of MMA $k_{\mathrm{t}}$ with $c_{\mathrm{I}}$. Further, it is noteworthy that the STY results of Figure $2\left(k_{\mathrm{t}}\right.$ versus $\left.c_{\mathrm{I}}\right)$ and of Figure $3\left(k_{\mathrm{t}}\right.$ versus $\left.c_{\mathrm{M}}\right)$ both return the same value of $a$, and hence of $\alpha$. In other words, there is self-consistency in results. On the other hand, there is no denying that the results of Figure 3 still fall well short of finding $\alpha \cdot 0.16$. One may posit reasons for this along the lines of those in the preceding subsection. Some of these remain valid. For example, CLDP will have the greatest effect at lowest $c_{\mathrm{M}}$ (when $D P_{\mathrm{n}}$ is smallest), meaning that the real variation of $k_{\mathrm{t}}$ with $c_{\mathrm{M}}$ could be stronger than deduced assuming constant $k_{\mathrm{p}}$. Others now go in the wrong direction. For example, any exotherm effect will be strongest at highest $c_{\mathrm{M}}$ (when rate is greatest), which would act to reduce the deduced variation of $k_{\mathrm{t}}$.

One new angle that should be discussed is that EB does not exactly mimic STY: its viscosity will be slightly different (affecting $k_{\mathrm{t}}^{1,1}$ ), while its solvent power may not be identical $(\alpha)$. Also relevant may be that the ethyl group of EB is more likely to participate in chain transfer than is the olefinic group of STY. If $C_{\mathrm{tr}}$ for transfer to EB is higher than for transfer to STY, then replacing STY with EB will result in faster generation of small free radicals, which will result in higher $k_{\mathrm{t}}{ }^{[24]}$ Thus the measured variation of $k_{\mathrm{t}}$ will be stronger than that due to $c_{\mathrm{M}}$ alone. So this possibility cannot explain that the measured $a$ is lower than should be the case.

\section{Variation of $k_{\mathrm{t}}$ with Temperature}

Equation (10) suggests that, because of possible variation of $k_{\mathrm{t}}$ with $c_{\mathrm{I}}$ and $c_{\mathrm{M}}$, one should endeavor to determine the activation energy of $k_{\mathrm{t}}, E_{\mathrm{a}}\left(k_{\mathrm{t}}\right)$, by carrying out experiments at constant $c_{\mathrm{I}}$ and, as far as possible, constant $c_{\mathrm{M}}$. This has not generally been the case in the literature, with workers tending to reduce $c_{\mathrm{I}}$ as temperature is increased in order to keep the increase in overall polymerization rate in check. However in this work we were careful to 
follow this dictum: series of bulk polymerizations with identical wt. \% AIBN were carried out. These results are given in Tables 1 and 2, and several series have been plotted in Figure 4. Parameters from the resulting Arrhenius fits are given in Table 4.

It is evident from both Figure 4 and Table 4 that we find no significant variation of Arrhenius parameters with wt. \% AIBN. This is not surprising given the weak dependence of $k_{\mathrm{t}}$ with $c_{\mathrm{I}}$ found earlier in this work (see Figure 2). Therefore it seems justified to combine all results for each monomer, independent of $c_{\mathrm{I}}$, and present the resulting Arrhenius fits as correlations for use by workers. These overall fits are presented in Figure 5 and are (see also Table 4)

$$
\begin{aligned}
& k_{\mathrm{t}}(\mathrm{MMA})=1.984 \times 10^{8} \mathrm{~L} \cdot \mathrm{mol} \cdot \mathrm{s}^{-1} \exp \left(\frac{-5.89 \mathrm{~kJ} \cdot \mathrm{mol}^{-1}}{R T}\right), 30 \leq \theta /{ }^{\circ} \mathrm{C} \leq 90 \\
& k_{\mathrm{t}}(\mathrm{STY})=1.341 \times 10^{10} \mathrm{~L} \cdot \mathrm{mol} \cdot \mathrm{s}^{-1} \exp \left(\frac{-14.34 \mathrm{~kJ} \cdot \mathrm{mol}^{-1}}{R T}\right), 40 \leq \theta /{ }^{\circ} \mathrm{C} \leq 90
\end{aligned}
$$

Of course one should be aware in using the above equations that $k_{\mathrm{t}}$ depends not just on temperature, but also on $D P_{\mathrm{n}} \cdot{ }^{[6]}$ However the latter variation has not been sufficiently manifest in this work, as already discussed. Similarly, values of $k_{\mathrm{t}}$ from the above equations should only be used within the given temperature ranges and for low-conversion bulk polymerizations.

We now turn to searching for meaning in the values of $E_{\mathrm{a}}\left(k_{\mathrm{t}}\right)$ that have been found above. From Equation (10) one has that

$$
E_{\mathrm{a}}\left(k_{\mathrm{t}}\right)=(1+a) \cdot E_{\mathrm{a}}\left(k_{\mathrm{t}}^{1,1}\right)+a \cdot E_{\mathrm{a}}\left(f k_{\mathrm{d}}\right)-2 a \cdot E_{\mathrm{a}}\left(k_{\mathrm{p}}\right)-2 a \cdot E_{\mathrm{a}}\left(c_{\mathrm{M}}\right)
$$

where $a$ remains as defined in Equation (12). Equation (15) assumes constant $c_{\mathrm{I}}$ and $\alpha$. The latter assumption is potentially flawed, as there have been measurements on styrene 
suggesting that $\alpha_{\mathrm{L}}$ decreases with increasing temperature. ${ }^{[61]}$ However in several studies of methacrylates, ${ }^{[9,11,18]}$ including MMA,${ }^{[18]}$ Buback et al. are yet to find any definite variation of either $\alpha_{\mathrm{S}}$ or $\alpha_{\mathrm{L}}$ with temperature, which tends to justify the assumption of constant $\alpha$. Even with this assumption, it is evident that $E_{\mathrm{a}}\left(k_{\mathrm{t}}\right)$ is a far more complicated parameter than is realized by virtually all workers, because chain-length-dependent termination means that the activation energy of both initiation and propagation enter into determining $E_{\mathrm{a}}\left(k_{\mathrm{t}}\right)$. This complexity is illustrated in Figure 6, which shows evaluations of Equation (15) using best estimates of all constituent activation energies for both MMA and STY. The values used are listed in Table 5. Some background on the $E_{\mathrm{a}}\left(k_{\mathrm{t}}^{1,1}\right)$ values is warranted. Using the SP-PLPEPR technique, Barth and Buback have recently measured $E_{\mathrm{a}}\left(k_{\mathrm{t}}^{1,1}\right)=9.0 \mathrm{~kJ} \cdot \mathrm{mol}^{-1}$ for MMA, ${ }^{[18]}$ a result that agrees remarkably with measurements of $E_{\mathrm{a}}\left(1 / \eta_{\mathrm{MMA}}\right)$, i.e., activation energy of inverse viscosity of pure MMA: $8.9^{[62]}$ and $9^{[63]} \mathrm{kJ} \cdot \mathrm{mol}^{-1}$. For STY we have used $E_{\mathrm{a}}\left(k_{\mathrm{t}}^{1,1}\right)=10.9 \mathrm{~kJ} \cdot \mathrm{mol}^{-1}$, this being the measured activation energy for self-diffusion of pure toluene. ${ }^{[64]}$ It seems reasonable to assume that diffusion of styrene molecules, and thus $k_{\mathrm{t}}^{1,1}$ for STY, must have a very similar activation energy.

Figure 6 shows that at $\alpha=0$ (chain-length-independent termination), $E_{\mathrm{a}}\left(k_{\mathrm{t}}\right)=E_{\mathrm{a}}\left(k_{\mathrm{t}}^{1,1}\right)$. Thus STY is slightly above MMA. However this advantage is eroded (see Equation (15)) with increasing $\alpha$ because of STY's $E_{\mathrm{a}}\left(k_{\mathrm{p}}\right)$, which is larger by about $10 \mathrm{~kJ} \cdot \mathrm{mol}^{-1}$ than MMA's. There is parity at $\alpha \bullet 0.18$, and thereafter MMA is predicted to have a higher $E_{\mathrm{a}}\left(k_{\mathrm{t}}\right)$. For both monomers the value of $E_{\mathrm{a}}\left(k_{\mathrm{t}}\right)$ rises monotonically with $\alpha$, an effect that is due to the large value of $E_{\mathrm{a}}\left(f k_{\mathrm{d}}\right)$, which results in higher fractions of the radical population being small as temperature increases, and hence in $k_{\mathrm{t}}$ being strongly increasing. ${ }^{[28]}$ Thus the only way to explain $E_{\mathrm{a}}\left(k_{\mathrm{t}}\right)<E_{\mathrm{a}}\left(k_{\mathrm{t}}^{1,1}\right)$ is if $E_{\mathrm{a}}\left(f k_{\mathrm{d}}\right)$ is very small, for example it would have to be $30 \mathrm{~kJ} \cdot \mathrm{mol}^{-1}$ or less with the MMA parameters of Table 5. It has previously been noted that this may be relevant where photochemical initiation has been used to measure $k_{\mathrm{t} .}{ }^{[28]}$ However for the more 
usual case of thermally induced initiation, one should expect $E_{\mathrm{a}}\left(k_{\mathrm{t}}\right)>E_{\mathrm{a}}\left(k_{\mathrm{t}}^{1,1}\right)$. Further, because $\alpha$ can be expected to increase with conversion, ${ }^{[41,48]}$ Figure 6 shows that $E_{\mathrm{a}}\left(k_{\mathrm{t}}\right)$ should increase with conversion. In fact this increase will be even stronger than calculated in Figure 6, because measurements of small-molecule diffusion coefficients show that $E_{\mathrm{a}}\left(k_{\mathrm{t}}^{1,1}\right)$ increases with conversion, ${ }^{[64]}$ an effect not included in the present calculations.

Considering now our experimental results, the $\alpha=0.16$ values of Figure 6 are 17.1 $\mathrm{kJ} \cdot \mathrm{mol}^{-1}$ for STY and $16.8 \mathrm{~kJ} \cdot \mathrm{mol}^{-1}$ for MMA. Obviously it is most pleasing to discuss the STY prediction first, because it is remarkably close to what has been found in the experiments of this work (see Table 4). Admittedly Figure 6 shows that $E_{\mathrm{a}}\left(k_{\mathrm{t}}\right)$ does not depend strongly on $\alpha$ around this point. For example, with $\alpha=0.10$ the prediction is $E_{\mathrm{a}}\left(k_{\mathrm{t}}\right)=$ 14.7 $\mathrm{kJ} \cdot \mathrm{mol}^{-1}$, which is also very much consistent with the experiments of this work. So really all that is justified is to say that our measured $E_{\mathrm{a}}\left(k_{\mathrm{t}}\right)$ for bulk STY is consistent with a weak chain-length dependence of termination. However the key points are that the experimental data is consistent with chain-length-dependent termination of the expected magnitude, and that the measured $E_{\mathrm{a}}\left(k_{\mathrm{t}}\right)$ may not otherwise be explained, because it is simply too high to be an $E_{\mathrm{a}}\left(k_{\mathrm{t}}^{1,1}\right)$ value.

As already foreshadowed, the situation is not nearly so bullish for MMA, for which $E_{\mathrm{a}}\left(k_{\mathrm{t}}\right)$ has been measured to be smaller than $E_{\mathrm{a}}\left(k_{\mathrm{t}}^{1,1}\right)$ (see Tables 4 and 5). There is no reasonable way of explaining this, for it is not even consistent with chain-length-independent termination, as has been spelled out above. Of some comfort is that literature studies have also tended to find the same unusually low value of $E_{\mathrm{a}}\left(k_{\mathrm{t}}\right) \cdot 5 \mathrm{~kJ} \cdot \mathrm{mol}^{-1}$ for MMA, as will be seen in the following subsection. Is there an unrecognized systematic error that is common to these many MMA studies, or is there something fundamental about MMA kinetics that is not understood and which leads to low $E_{\mathrm{a}}\left(k_{\mathrm{t}}\right)$ ? While the latter should not be discounted, one tends to think the former is more likely, because methods that directly probe the chain-length 
dependence of termination have found expected behavior for MMA, ${ }^{[17-19]}$ as opposed to anything that might lead an almost-zero value of $E_{\mathrm{a}}\left(k_{\mathrm{t}}\right)$.

What possible reasons are there for measuring a very low $E_{\mathrm{a}}\left(k_{\mathrm{t}}\right)$ for MMA? Obviously one may pursue the possibilities advanced in the preceding subsections for discrepancies between experiment and expectation. A new one to mention here is the possibility of significant initiator consumption. Throughout this work it has been assumed that $c_{\mathrm{I}}$ was constant at its initial value during experiments. At higher temperatures this may not have been the case, meaning there is the possibility that the effective $c_{\mathrm{I}}$ became lower as temperature was increased. Another possibility is that, as already mentioned, $\alpha_{\mathrm{L}}$ may decrease with temperature, ${ }^{[61]}$ contrary to what has been assumed in making theoretical predictions above. However, lower $\alpha$ will lead to higher $k_{\mathrm{t}}$ (see Equation (10)), for example $k_{\mathrm{t}}$ $=k_{\mathrm{t}}^{1,1}$ in the limit of $\alpha=0$. So $\alpha$ decreasing with temperature should actually increase $E_{\mathrm{a}}\left(k_{\mathrm{t}}\right)$ above and beyond the predictions of Equation (15), which is contrary to what has been observed here with MMA.

One problem with all the above explanations is that if they apply to MMA, then they should also apply to STY, for example differential initiator consumption (since AIBN was used for both monomers in this work). Thus it is very difficult to explain that MMA returns unexpected results for $E_{\mathrm{a}}\left(k_{\mathrm{t}}\right)$ but STY does not. So the bottom line is that there are mysteries about the fine details of MMA experimental results for $k_{\mathrm{t}}$.

\section{Comparison with Literature Values}

Figure 7 shows all $k_{\mathrm{t}}$ values for MMA tabulated in the 1989 edition of the Polymer Handbook, ${ }^{[65]}$ and in addition the best fit to the values of this work (Equation (14a)). For STY the picture would be essentially the same. What Figure 7 first of all shows is the enormous scatter of literature values of $k_{\mathrm{t}}{ }^{[25]}$ This means that almost whatever values of $k_{\mathrm{t}}$ one 
measures, corroboration from the literature can be found. Nevertheless the comparison carried out in Figure 7 is not meaningless, because it is a positive sign that the $k_{\mathrm{t}}$ fit from this work lies very close to the best fit of all the literature values, as shown. This is even more so the case when one bears in mind that a good proportion of the literature $k_{\mathrm{t}}$ values will be too high by a factor of 2 because of having been determined using $-k_{\mathrm{t}} c_{\mathrm{R}}^{2}$ as the rate law for termination, as opposed to the IUPAC-recommended ${ }^{[25]}-2 k_{\mathrm{t}} c_{\mathrm{R}}^{2}$ that has been used in this work (see Equation (1)).

In view of the scatter in Figure 7, it was decided to carry out a more discerning comparison of values from the literature with those of this work. Well-known studies ${ }^{[30,39,43,49,59,66-72]}$ using a variety of methods were selected without bias. Most of these studies are subsequent to the compilation ${ }^{[25]}$ used to generate Figure 7 . Where necessary reported values have been divided by 2 in order to make them consistent with the rate law $-2 k_{\mathrm{t}} c_{\mathrm{R}}^{2}$. In two very early works ${ }^{[39,70]}$ the $k_{\mathrm{p}}$ values were so blatantly in error that $k_{\mathrm{t}}$ was recalculated from the obtained $k_{\mathrm{p}} / k_{\mathrm{t}}$ with Equation (3), it having been shown that the use of incorrect $k_{\mathrm{p}}$ in data analysis is a significant source of error in reported $k_{\mathrm{t}}$ values. ${ }^{[25]}$ However in no other case was this done.

These more refined comparisons with literature data are shown in Figure 8 (MMA) and Figure 9 (STY). In both cases the agreement between literature values of $k_{\mathrm{t}}$ and those from the present work is more than acceptable. This may be taken as the desired confirmation that careful gravimetry, though a very simple experimental method, yields reliable $k_{\mathrm{t}}$ values within present limits of accuracy, even those of modern, PLP-based methods ${ }^{[43,49,68,72]}$ for obtaining overall $k_{\mathrm{t}}$. This is not to say that the present limits of accuracy are entirely satisfactory, as is immediately evident from an honest appraisal of Figures 5, 8 and 9, which give a picture of the error levels both in this work (Figure 5) and the scrutinized literature (Figures 8 and 9). However at least the situation in Figures 5,8 and 9 is a vast improvement 
on that in Figure 7 ! Further, understanding is growing that what may at first appear to be perplexing error in $k_{\mathrm{t}}$ is often just a manifestation of the many factors on which $k_{\mathrm{t}}$ depends, ${ }^{[6,25]}$ as should be clear from the discussions of this work.

Especially pleasing about Figures 8 and 9 is that they make clear that the $E_{\mathrm{a}}\left(k_{\mathrm{t}}\right)$ found in the present work are broadly consistent with those found in literature studies. In particular, other workers have also found that $E_{\mathrm{a}}\left(k_{\mathrm{t}}, \mathrm{STY}\right)>E_{\mathrm{a}}\left(k_{\mathrm{t}}, \mathrm{MMA}\right)$ and that $E_{\mathrm{a}}\left(k_{\mathrm{t}}, \mathrm{MMA}\right)$ is surprisingly small. This is relevant in terms of the discussion of the preceding subsection.

Lastly, one matter that is rarely mentioned in the literature is the impact of assumed $f k_{\mathrm{d}}$ on experimental values of $k_{\mathrm{t}}$. This is because it has traditionally been regarded as easy to obtain accurate $f k_{\mathrm{d}}$, whether from the literature or by measurement oneself. However now that accurate $k_{\mathrm{p}}$ are readily available in cases like the present one, the question arises as to whether $f k_{\mathrm{d}}$ is a significant source of error in $k_{\mathrm{t}}$ determination via steady-state methods (as opposed to non-stationary methods, which have the advantage of yielding $k_{\mathrm{p}} / k_{\mathrm{t}}$ without input of any initiation parameters, unless there is significant dark-time initiation $\left.{ }^{[22]}\right)$. The issue is the very large activation energy of $f k_{\mathrm{d}}$. For example, an error of $1 \mathrm{~kJ} \cdot \mathrm{mol}^{-1}$ in $E_{\mathrm{a}}\left(f k_{\mathrm{d}}\right)$ is less than $1 \%$ of the value used in this work (123.5 $\mathrm{kJ} \cdot \mathrm{mol}^{-1}$, see Equation (4)), which by any measure is a small error. However sample calculations, admittedly with unchanged $A\left(f k_{\mathrm{d}}\right)$ (see further comment below), showed that such an error would lead to $k_{\mathrm{t}}$ values of the present work being altered by up to $50 \%$, which is a huge effect.

The relevance here is that $E_{\mathrm{a}}\left(k_{\mathrm{d}}\right)$ for an initiator may easily vary by $10 \mathrm{~kJ} \cdot \mathrm{mol}^{-1}$ depending on the solvent. ${ }^{[32]}$ Of course as is the usual way with Arrhenius parameters, as $E_{\mathrm{a}}\left(k_{\mathrm{d}}\right)$ increases there is also increase of $A\left(k_{\mathrm{d}}\right),{ }^{[32]}$ so that the effect of $E_{\mathrm{a}}$ change on the value of $k_{\mathrm{d}}$ is largely counterbalanced, meaning that error in experimental $k_{\mathrm{t}}$ will not be so large, since Equation (2) makes clear that $k_{\mathrm{t}} \sim f k_{\mathrm{d}}$. However this result also means than any error in the assumed $E_{\mathrm{a}}\left(f k_{\mathrm{d}}\right)$ is directly transferred to $E_{\mathrm{a}}\left(k_{\mathrm{t}}\right)$. For example, if the $E_{\mathrm{a}}\left(f k_{\mathrm{d}}\right)$ used to process 
steady-state rate data is $5 \mathrm{~kJ} \cdot \mathrm{mol}^{-1}$ too low, then $k_{\mathrm{t}}$ will be obtained that has $E_{\mathrm{a}}\left(k_{\mathrm{t}}\right)$ too low by this same amount. It seems likely that this is of general relevance and that in particular it may be relevant to the MMA results of this work, given that the $E_{\mathrm{a}}\left(f k_{\mathrm{d}}\right)$ value used was obtained for AIBN in STY.

\section{The Difference between Styrene and Methyl Methacrylate}

It is visually evident from the figures of this work that $k_{\mathrm{t}}$ for STY has been measured to be several times higher than that for MMA. This is mathematically confirmed by Equations (14a) and (14b), which return $k_{\mathrm{t}}(\mathrm{STY}) / k_{\mathrm{t}}(\mathrm{MMA})$ of 2.6 at $40{ }^{\circ} \mathrm{C}$ increasing up to 4.1 at $90{ }^{\circ} \mathrm{C}$. Importantly, this is also the case in the literature: where the same workers have used the same method to determine $k_{\mathrm{t}}$ for both monomers, they have generally found similar ratios to those just quoted, as is evident from Figures 8 and 9. For example, Fukuda et al. measured (averages of quoted values) $4.3 \times 10^{7} / 1.5 \times 10^{7}=2.9$ at $40{ }^{\circ} \mathrm{C},{ }^{[30]}$ which is remarkably close to the ratio from this work.

The question arises: why this difference? This is not often contemplated, and insofar as it is, consideration is usually only given to radical-radical encounter, for example polymer diffusion and shielding. However Equation (10) reveals that the matter may be rather different, for this equation contains that

$$
k_{\mathrm{t}} \sim\left(k_{\mathrm{t}}^{1,1}\right)^{1+a}\left(f k_{\mathrm{d}}\right)^{a}\left(k_{\mathrm{p}} c_{\mathrm{M}}\right)^{-2 a}
$$

There is a term here that is directly associated with radical-radical encounter, namely $k_{\mathrm{t}}^{1,1}$. However this term is not as straightforward as it at first seems, as will presently be explained. Further, there are two other terms in Equation (16) that do not have anything to do with radical-radical encounter: a consequence of chain-length-dependent termination is that $k_{\mathrm{t}}$ depends also on $k_{\mathrm{p}} c_{\mathrm{M}}$ and $f k_{\mathrm{d}}$. In the former case this is because the slower the growth of 
radicals, the longer they exist as more rapidly terminating small radicals, and hence the higher the value of $k_{\mathrm{t}}$. Thus even if all else is equal, a monomer with low $k_{\mathrm{p}}$, e.g. STY, will have a higher $k_{\mathrm{t}}$ than one with higher $k_{\mathrm{p}}$, e.g. MMA, as was first pointed out some years ago. ${ }^{[28]}$ In the case of $f k_{\mathrm{d}}$, the effect is that the higher the rate of initiation, the greater is the fraction of radicals that are small, and so the higher is $k_{\mathrm{t} \cdot}{ }^{[51]}$ Each of the three terms in Equation (16) will now be considered in relation to values of $k_{\mathrm{t}}$ for MMA and STY.

As was discussed in presenting Equation (4), there is some evidence that $f k_{\mathrm{d}}$ may be slightly higher for AIBN in STY than in MMA. The measured ratio of values is 1.39 at 40 ${ }^{\circ} \mathrm{C} .{ }^{[30]}$ Using $\alpha=0.16$, Equations $(12)$ and (16) then lead to $k_{\mathrm{t}}(\mathrm{STY}) / k_{\mathrm{t}}(\mathrm{MMA})=1.39^{0.087}=$ 1.03. While this is qualitatively in the right direction, the magnitude of the effect, even allowing for uncertainties in $f k_{\mathrm{d}}$ and $\alpha$, is clearly far too small to explain single-handedly the observed values of $k_{\mathrm{t}}(\mathrm{STY}) / k_{\mathrm{t}}(\mathrm{MMA})$.

With propagation more traction is gained, because $k_{\mathrm{p}} c_{\mathrm{M}}$ differences are greater and the exponent in Equation (16) is $2 a$ rather than $a$. Specifically, the equations of this work give $k_{\mathrm{p}} c_{\mathrm{M}}(\mathrm{MMA}) / k_{\mathrm{p}} c_{\mathrm{M}}(\mathrm{STY})=3.34$ at $40{ }^{\circ} \mathrm{C}$ decreasing to 1.93 at $90{ }^{\circ} \mathrm{C}$. The vast majority of this effect is due to $k_{\mathrm{p}}$, but there is a small extra component due to MMA having higher $c_{\mathrm{M}}$. Together with $\alpha=0.16$, these values used in Equation (16) lead to $k_{\mathrm{t}}(\mathrm{STY}) / k_{\mathrm{t}}(\mathrm{MMA})=1.23$ at $40{ }^{\circ} \mathrm{C}$ decreasing to 1.12 at $90{ }^{\circ} \mathrm{C}$. This is qualitatively in the right direction and is more significant in magnitude than with $f k_{\mathrm{d}}$, but it is still not quantitatively enough to explain the experimental differences in $k_{\mathrm{t}}$ (as quoted above). Further, the change in the ratio with temperature (decreasing) is opposite to that observed experimentally (increasing). Nevertheless it seems undeniable that $k_{\mathrm{p}}$ differences must be a significant factor in explaining the differences in $k_{\mathrm{t}}$ values between STY and MMA, especially since the same trend - i.e., higher $k_{\mathrm{t}}$ where $k_{\mathrm{p}}$ is lower - is seen with other monomer pairs that are otherwise quite similar. $^{[28]}$ 
It is tempting to employ $\alpha \cdot 0.5$ in Equation (16) in order to explain $k_{\mathrm{t}}$ differences, because this value of $\alpha$ holds for small MMA and STY chains, and clearly it will result in $k_{\mathrm{p}} c_{\mathrm{M}}$ differences having a stronger quantitative effect on $k_{\mathrm{t}}$. For example, using $\alpha=0.5$ in the calculations of the previous paragraph gives $k_{\mathrm{t}}(\mathrm{STY}) / k_{\mathrm{t}}(\mathrm{MMA})=2.23$ at $40{ }^{\circ} \mathrm{C}$, which is very close to the experimental value (2.6) from this work. However there is no justification for using $\alpha=0.5$ in this way, except where very short chains $\left(D P_{\mathrm{n}} \cdot 100\right.$ or less $)$ are being produced, ${ }^{[40]}$ which is not the case here. For one thing, calculations have shown that the composite model still results in $\alpha_{\mathrm{L}}$ being the value of $\alpha$ that is relevant for $k_{\mathrm{t}}$ behavior where $D P_{\mathrm{n}}>i_{\mathrm{c} .}{ }^{[6,21]}$ Further, there is also the empirical evidence of works like this one, which find no evidence for $\alpha>\alpha_{\mathrm{L}}$ describing $k_{\mathrm{t}}$.

Nevertheless $\alpha_{\mathrm{S}}$ must obviously have some effect on the value of $k_{\mathrm{t}}$. How? The answer is that $k_{\mathrm{t}}^{1,1}$ in Equations (10) and (16) is not to be seen as the true value of $k_{\mathrm{t}}^{1,1}$, but rather as the value if long-chain values of $k_{\mathrm{t}}^{i, i}$ are extrapolated back to $i=1 .{ }^{[6,21]} \mathrm{By}$ comparing the second line of Equation (8) with Equation (9), one can understand the result ${ }^{[6]}$

$$
k_{\mathrm{t}}^{1,1}(\text { apparent }) \approx k_{\mathrm{t}}^{1,1}(\text { true }) \times\left(i_{\mathrm{c}}\right)^{-\alpha_{\mathrm{S}}+\alpha_{\mathrm{L}}}
$$

One now sees how all the parameters of the composite model for termination, not just $\alpha_{\mathrm{L}}$ and $k_{\mathrm{t}}^{1,1}$ (true), influence the value of $k_{\mathrm{t}}$.

The value of $k_{\mathrm{t}}^{1,1}$ (true), which is the actual value of $k_{\mathrm{t}}$ for monomeric radicals, is given by the Smoluchowski equation for diffusion-controlled reactions. ${ }^{[6,73]}$ Thus one needs to consider monomer size and diffusion. MMA and STY have nearly identical molar mass, and are therefore of similar molecular size. Some determined diffusion coefficients $\left(/ 10^{-9} \mathrm{~m}^{2} \cdot \mathrm{s}^{-1}\right)$ at $25{ }^{\circ} \mathrm{C}$ are: benzene: $2.19 ;{ }^{[48]}$ toluene: $2.0,{ }^{[48]} 2.16^{[74]}$ and $2.66 ;^{[64]}$ cyclohexane: $1.47 ;^{[48]}$ STY: $1.5 ;^{.75]}$ ethylbenzene: $1.79 .{ }^{[74]}$ and MMA: $2.25^{[74]}$ and $2.1-3.1 .^{[41]}$ On the basis of this data there is no reason to think that $k_{\mathrm{t}}^{1,1}$ (true) is higher for STY than for MMA, in fact if 
anything the opposite is likely to be the case. So STY's higher $k_{\mathrm{t}}$ cannot be due to monomeric termination rate coefficients.

As mentioned earlier in this paper, there is evidence that $\alpha_{\mathrm{S}}$ and $i_{\mathrm{c}}$ are different for MMA and STY. For MMA the values $\alpha_{\mathrm{S}} \cdot 0.65$ and $i_{\mathrm{c}} \cdot 100$ are reasonably well established. ${ }^{[17-19]}$ Results for STY are not as clear, but indications are that $\alpha_{\mathrm{S}} \bullet 0.5$ and $i_{\mathrm{c}} \bullet$ $30-50 .{ }^{[15,16,20]}$ Using $\alpha_{\mathrm{L}}=0.16, \alpha_{\mathrm{S}}(\mathrm{MMA})=0.65$ and $\alpha_{\mathrm{S}}(\mathrm{STY})=0.5$, one obtains from Equation (17) that $k_{\mathrm{t}}^{1,1}\left(\right.$ apparent,STY) $/ k_{\mathrm{t}}^{1,1}($ apparent,MMA $)=1.80$ with $i_{\mathrm{c}}=50,2.00$ with $i_{\mathrm{c}}=$ 100 , and 2.53 with $i_{\mathrm{c}}(\mathrm{STY})=50$ and $i_{\mathrm{c}}(\mathrm{MMA})=100$. One should remember that these ratios will translate into a slightly larger value still of $k_{\mathrm{t}}(\mathrm{STY}) / k_{\mathrm{t}}(\mathrm{MMA})$ because of the raising power of $1+a$ in Equation (16). Given these calculations, it seems reasonable to conclude that $\alpha_{\mathrm{S}}$ differences, possibly boosted by $i_{\mathrm{c}}$ differences, are primarily responsible for the difference in magnitude between $k_{\mathrm{t}}$ values for STY and MMA. In physical terms the reason for this is that although STY and MMA start out with similar $k_{\mathrm{t}}^{i, i}$ for $i=1$, the higher $\alpha_{\mathrm{S}}$ of MMA means that its $k_{\mathrm{t}}^{i, i}$ values become less and less than STY's as $i$ increases, an effect that will be exacerbated at long chain lengths if $i_{\mathrm{c}}$ is smaller for STY (meaning that the weaker chainlength dependence at long chain lengths sets in at an earlier point). Variations of $\alpha_{\mathrm{S}}$ and $i_{\mathrm{c}}$ with temperature - about which essentially nothing is known - may conceivably be responsible for $E_{\mathrm{a}}\left(k_{\mathrm{t}}\right)$ being different for MMA and STY.

In summary, the major cause of STY $k_{\mathrm{t}}$ being higher than MMA $k_{\mathrm{t}}$ by a factor of approximately 3 seems likely to be MMA's stronger chain-length dependence of $k_{\mathrm{t}}^{i, i}$ at small chain lengths. This finding has relevance for acrylates, which are characterized by $\alpha_{\mathrm{S}} \cdot 1 .^{[6,76]}$ There are smaller but still significant contributions to the STY-MMA $k_{\mathrm{t}}$ difference from $k_{\mathrm{p}}$ and possibly $i_{\mathrm{c}}$. Again, this has relevance for acrylates given that they have very large $k_{\mathrm{p} .}{ }^{[77]}$ 
Although not considered here, it goes without saying that $\alpha_{\mathrm{L}}$ differences will also affect values of $k_{\mathrm{t}}$ (see Equation (10)).

\section{Conclusion}

Many are the causes of complexity in radical polymerization kinetics, but by far the most important, the most pervasive and the most complicated is chain-length-dependent termination. Numerous workers have set out with the expectation of explaining all in this regard. Without exception they have suffered mystifying defeats, and at best they have had to settle for a few hard-won victories at a time. That also describes this work. However it has been shown that with time these little victories have continued to add up, and that they have thereby contributed to the emergence of a picture of ever increasing clarity. ${ }^{[6]}$ There is every reason to expect that this will also be the case with the present work.

Acknowledgments: Mr. Dave Macdonald and Mr. Rob McGregor are thanked for their skillful and ever available glassblowing. KYvB appreciates the support of a New Zealand Foundation for Research Science and Technology Bright Future Scholarship, a Shirtcliffe Fellowship, and the P.A. Rolfe Scholarship Fund. MMA is grateful to King Khalid University (Saudi Arabia) for financial support. On this auspicious occasion GTR wishes to congratulate Prof. Dr. Michael Buback on his immense contributions to the detailed study of radical polymerization reactions, and he thanks him for his mentorship and friendship over two decades of a common and collaborative search for the truth. 
Keywords: termination; kinetics (polym.); methyl methacrylate; styrene; radical polymerization 
Table 1. Results from low-conversion, bulk polymerizations of methyl methacrylate with AIBN concentration $c_{\text {AIBN }}$. The experimentally determined quantity $k_{0}$, defined by Equation (1), has been used to calculate termination rate coefficient, $k_{t}$, according to Equation (2). Number-average degree of polymerization, $D P_{\mathrm{n}}$, has been estimated via Equation (5).

\begin{tabular}{|c|c|c|c|c|c|}
\hline $\begin{array}{c}\text { Temperature } \\
\left({ }^{\circ} \mathrm{C}\right)\end{array}$ & wt. $\%$ AIBN & $\begin{array}{c}c_{\mathrm{AIBN}} \\
\left(\mathrm{mol} \cdot \mathrm{L}^{-1}\right)\end{array}$ & $\begin{array}{c}k_{\mathrm{o}} \\
\left(\mathrm{s}^{-1}\right)\end{array}$ & $\begin{array}{c}k_{\mathrm{t}} \\
\left(\mathrm{L} \cdot \mathrm{mol}^{-1} \cdot \mathrm{s}^{-1}\right)\end{array}$ & $D P_{\mathrm{n}}$ \\
\hline 30 & 1.00 & $5.76 \times 10^{-2}$ & $4.84 \times 10^{-6}$ & $1.84 \times 10^{7}$ & $8.56 \times 10^{3}$ \\
\hline 30 & 1.00 & $5.75 \times 10^{-2}$ & $5.03 \times 10^{-6}$ & $1.71 \times 10^{7}$ & $8.89 \times 10^{3}$ \\
\hline 40 & 0.01 & $5.70 \times 10^{-4}$ & $1.52 \times 10^{-6}$ & $1.57 \times 10^{7}$ & $3.98 \times 10^{4}$ \\
\hline 40 & 0.01 & $5.66 \times 10^{-4}$ & $1.38 \times 10^{-6}$ & $1.89 \times 10^{7}$ & $3.75 \times 10^{4}$ \\
\hline 40 & 0.10 & $5.70 \times 10^{-3}$ & $3.65 \times 10^{-6}$ & $2.70 \times 10^{7}$ & $1.27 \times 10^{4}$ \\
\hline 40 & 1.00 & $5.74 \times 10^{-2}$ & $1.30 \times 10^{-5}$ & $2.15 \times 10^{7}$ & $4.81 \times 10^{3}$ \\
\hline 50 & 0.01 & $5.70 \times 10^{-4}$ & $2.95 \times 10^{-6}$ & $3.05 \times 10^{7}$ & $2.04 \times 10^{4}$ \\
\hline 50 & 0.01 & $5.77 \times 10^{-4}$ & $3.39 \times 10^{-6}$ & $2.35 \times 10^{7}$ & $2.24 \times 10^{4}$ \\
\hline 50 & 0.01 & $5.69 \times 10^{-4}$ & $3.50 \times 10^{-6}$ & $2.17 \times 10^{7}$ & $2.32 \times 10^{4}$ \\
\hline 50 & 0.10 & $5.70 \times 10^{-3}$ & $1.39 \times 10^{-5}$ & $1.38 \times 10^{7}$ & $1.08 \times 10^{4}$ \\
\hline 50 & 0.10 & $5.49 \times 10^{-3}$ & $1.08 \times 10^{-5}$ & $2.22 \times 10^{7}$ & $8.91 \times 10^{3}$ \\
\hline 50 & 0.10 & $5.66 \times 10^{-3}$ & $1.03 \times 10^{-5}$ & $2.47 \times 10^{7}$ & $8.37 \times 10^{3}$ \\
\hline 50 & 1.00 & $5.75 \times 10^{-2}$ & $3.36 \times 10^{-5}$ & $2.38 \times 10^{7}$ & $2.85 \times 10^{3}$ \\
\hline 60 & 0.01 & $5.66 \times 10^{-4}$ & $8.31 \times 10^{-6}$ & $2.51 \times 10^{7}$ & $1.46 \times 10^{4}$ \\
\hline 60 & 0.01 & $5.65 \times 10^{-4}$ & $8.36 \times 10^{-6}$ & $2.47 \times 10^{7}$ & $1.47 \times 10^{4}$ \\
\hline 60 & 0.10 & $5.75 \times 10^{-3}$ & $2.71 \times 10^{-5}$ & $2.39 \times 10^{7}$ & $5.44 \times 10^{3}$ \\
\hline 60 & 0.10 & $5.70 \times 10^{-3}$ & $2.56 \times 10^{-5}$ & $2.65 \times 10^{7}$ & $5.21 \times 10^{3}$ \\
\hline 60 & 0.10 & $5.70 \times 10^{-3}$ & $2.73 \times 10^{-5}$ & $2.34 \times 10^{7}$ & $5.52 \times 10^{3}$ \\
\hline 60 & 0.10 & $5.66 \times 10^{-3}$ & $2.76 \times 10^{-5}$ & $2.27 \times 10^{7}$ & $5.62 \times 10^{3}$ \\
\hline 60 & 1.00 & $5.69 \times 10^{-2}$ & $7.88 \times 10^{-5}$ & $2.80 \times 10^{7}$ & $1.69 \times 10^{3}$ \\
\hline 60 & 1.00 & $5.76 \times 10^{-2}$ & $9.96 \times 10^{-5}$ & $1.77 \times 10^{7}$ & $2.10 \times 10^{3}$ \\
\hline 60 & 1.00 & $5.76 \times 10^{-2}$ & $8.80 \times 10^{-5}$ & $2.27 \times 10^{7}$ & $1.86 \times 10^{3}$ \\
\hline
\end{tabular}




$\begin{array}{llllll}70 & 0.01 & 5.70 \times 10^{-4} & 1.66 \times 10^{-5} & 3.73 \times 10^{7} & 8.31 \times 10^{3} \\ 70 & 0.01 & 5.70 \times 10^{-4} & 2.36 \times 10^{-5} & 1.83 \times 10^{7} & 1.11 \times 10^{4} \\ 70 & 0.01 & 5.25 \times 10^{-4} & 1.70 \times 10^{-5} & 3.24 \times 10^{7} & 9.12 \times 10^{3} \\ 70 & 0.01 & 5.70 \times 10^{-4} & 2.07 \times 10^{-5} & 2.38 \times 10^{7} & 1.00 \times 10^{4} \\ 70 & 0.10 & 5.70 \times 10^{-3} & 5.86 \times 10^{-5} & 2.98 \times 10^{7} & 3.25 \times 10^{3} \\ 70 & 0.10 & 5.70 \times 10^{-3} & 6.31 \times 10^{-5} & 2.57 \times 10^{7} & 3.49 \times 10^{3} \\ 70 & 0.10 & 5.70 \times 10^{-3} & 5.53 \times 10^{-5} & 3.35 \times 10^{7} & 3.08 \times 10^{3} \\ 70 & 0.30 & 1.72 \times 10^{-2} & 1.14 \times 10^{-4} & 2.37 \times 10^{7} & 2.14 \times 10^{3} \\ 70 & 1.00 & 5.76 \times 10^{-2} & 2.20 \times 10^{-4} & 2.13 \times 10^{7} & 1.26 \times 10^{3} \\ 70 & 1.00 & 5.76 \times 10^{-2} & 2.11 \times 10^{-4} & 2.33 \times 10^{7} & 1.20 \times 10^{3} \\ 70 & 1.00 & 5.76 \times 10^{-2} & 2.02 \times 10^{-4} & 2.54 \times 10^{7} & 1.15 \times 10^{3} \\ 70 & 1.00 & 5.78 \times 10^{-2} & 2.08 \times 10^{-4} & 2.41 \times 10^{7} & 1.18 \times 10^{3} \\ 70 & 1.00 & 5.78 \times 10^{-2} & 1.87 \times 10^{-4} & 2.98 \times 10^{7} & 1.06 \times 10^{3} \\ 80 & 0.01 & 5.68 \times 10^{-4} & 4.83 \times 10^{-5} & 2.32 \times 10^{7} & 6.96 \times 10^{3} \\ 80 & 0.01 & 5.68 \times 10^{-4} & 4.65 \times 10^{-5} & 2.50 \times 10^{7} & 6.75 \times 10^{3} \\ 90 & 0.01 & 5.70 \times 10^{-4} & 1.02 \times 10^{-4} & 2.55 \times 10^{7} & 4.67 \times 10^{3} \\ 90 & 0.01 & 5.70 \times 10^{-4} & 1.05 \times 10^{-4} & 2.39 \times 10^{7} & 4.80 \times 10^{3}\end{array}$


Table 2. Results from low-conversion, bulk polymerizations of styrene with AIBN concentration $c_{\mathrm{AIBN}}$. The experimentally determined quantity $k_{\mathrm{o}}$, defined by Equation (1), has been used to calculate termination rate coefficient, $k_{\mathrm{t}}$, according to Equation (2). Numberaverage degree of polymerization, $D P_{\mathrm{n}}$, has been estimated via Equation (5).

\begin{tabular}{|c|c|c|c|c|c|}
\hline $\begin{array}{c}\text { Temperature } \\
\left({ }^{\circ} \mathrm{C}\right)\end{array}$ & wt. $\%$ AIBN & $\begin{array}{c}c_{\mathrm{AIBN}} \\
\left(\mathrm{mol} \cdot \mathrm{L}^{-1}\right)\end{array}$ & $\begin{array}{c}k_{\mathrm{o}} \\
\left(\mathrm{s}^{-1}\right) \\
\end{array}$ & $\begin{array}{c}k_{\mathrm{t}} \\
\left(\mathrm{L} \cdot \mathrm{mol}^{-1} \cdot \mathrm{s}^{-1}\right)\end{array}$ & $D P_{\mathrm{n}}$ \\
\hline 40 & 1.00 & $5.53 \times 10^{-2}$ & $3.48 \times 10^{-6}$ & $4.21 \times 10^{7}$ & $1.32 \times 10^{3}$ \\
\hline 40 & 1.00 & $5.59 \times 10^{-2}$ & $3.11 \times 10^{-6}$ & $5.33 \times 10^{7}$ & $1.17 \times 10^{3}$ \\
\hline 50 & 1.00 & $5.58 \times 10^{-2}$ & $9.25 \times 10^{-6}$ & $5.65 \times 10^{7}$ & $8.00 \times 10^{2}$ \\
\hline 50 & 1.00 & $5.59 \times 10^{-2}$ & $8.49 \times 10^{-6}$ & $6.72 \times 10^{7}$ & $7.35 \times 10^{2}$ \\
\hline 60 & 0.01 & $5.53 \times 10^{-4}$ & $2.30 \times 10^{-6}$ & $7.44 \times 10^{7}$ & $4.14 \times 10^{3}$ \\
\hline 60 & 0.01 & $5.53 \times 10^{-4}$ & $2.32 \times 10^{-6}$ & $7.29 \times 10^{7}$ & $4.18 \times 10^{3}$ \\
\hline 60 & 0.01 & $5.52 \times 10^{-4}$ & $2.24 \times 10^{-6}$ & $7.84 \times 10^{7}$ & $4.06 \times 10^{3}$ \\
\hline 60 & 0.10 & $5.54 \times 10^{-3}$ & $6.72 \times 10^{-6}$ & $8.74 \times 10^{7}$ & $1.40 \times 10^{3}$ \\
\hline 60 & 0.10 & $5.53 \times 10^{-3}$ & $6.48 \times 10^{-6}$ & $9.39 \times 10^{7}$ & $1.36 \times 10^{3}$ \\
\hline 60 & 0.10 & $5.54 \times 10^{-3}$ & $5.35 \times 10^{-6}$ & $1.38 \times 10^{8}$ & $1.13 \times 10^{3}$ \\
\hline 60 & 1.00 & $5.59 \times 10^{-2}$ & $2.34 \times 10^{-5}$ & $7.24 \times 10^{7}$ & $5.07 \times 10^{2}$ \\
\hline 60 & 1.00 & $5.56 \times 10^{-2}$ & $2.25 \times 10^{-5}$ & $7.83 \times 10^{7}$ & $4.89 \times 10^{2}$ \\
\hline 70 & 0.01 & $5.53 \times 10^{-4}$ & $5.93 \times 10^{-6}$ & $8.13 \times 10^{7}$ & $2.95 \times 10^{3}$ \\
\hline 70 & 0.01 & $5.53 \times 10^{-4}$ & $6.70 \times 10^{-6}$ & $6.37 \times 10^{7}$ & $3.25 \times 10^{3}$ \\
\hline 70 & 0.01 & $5.48 \times 10^{-4}$ & $6.01 \times 10^{-6}$ & $7.84 \times 10^{7}$ & $3.00 \times 10^{3}$ \\
\hline 70 & 0.10 & $5.54 \times 10^{-3}$ & $1.86 \times 10^{-5}$ & $8.27 \times 10^{7}$ & $1.05 \times 10^{3}$ \\
\hline 70 & 1.00 & $5.58 \times 10^{-2}$ & $6.08 \times 10^{-5}$ & $7.80 \times 10^{7}$ & $3.56 \times 10^{2}$ \\
\hline 70 & 1.00 & $5.54 \times 10^{-2}$ & $5.60 \times 10^{-5}$ & $9.14 \times 10^{7}$ & $3.31 \times 10^{2}$ \\
\hline 70 & 1.00 & $5.59 \times 10^{-2}$ & $5.20 \times 10^{-5}$ & $1.07 \times 10^{8}$ & $3.05 \times 10^{2}$ \\
\hline 80 & 0.01 & $5.51 \times 10^{-4}$ & $2.14 \times 10^{-5}$ & $4.03 \times 10^{7}$ & $2.93 \times 10^{3}$ \\
\hline 80 & 0.01 & $5.53 \times 10^{-4}$ & $1.25 \times 10^{-5}$ & $1.19 \times 10^{8}$ & $1.88 \times 10^{3}$ \\
\hline 80 & 0.01 & $5.52 \times 10^{-4}$ & $1.43 \times 10^{-5}$ & $9.13 \times 10^{7}$ & $2.10 \times 10^{3}$ \\
\hline
\end{tabular}




$\begin{array}{llllll}80 & 0.01 & 5.53 \times 10^{-4} & 1.33 \times 10^{-5} & 1.05 \times 10^{8} & 1.98 \times 10^{3} \\ 80 & 1.00 & 5.58 \times 10^{-2} & 1.35 \times 10^{-4} & 1.03 \times 10^{8} & 2.30 \times 10^{2} \\ 80 & 1.00 & 5.59 \times 10^{-2} & 1.46 \times 10^{-4} & 8.77 \times 10^{7} & 2.49 \times 10^{2} \\ 90 & 0.01 & 5.53 \times 10^{-4} & 3.10 \times 10^{-5} & 1.13 \times 10^{8} & 1.46 \times 10^{3} \\ 90 & 0.01 & 5.53 \times 10^{-4} & 3.11 \times 10^{-5} & 1.13 \times 10^{8} & 1.46 \times 10^{3}\end{array}$


Table 3. Results from low-conversion, solution polymerizations of styrene (STY) with AIBN concentration $c_{\mathrm{AIBN}}$. For all experiments the solvent was ethyl benzene, the temperature 50 ${ }^{\circ} \mathrm{C}$, and the wt. $\%$ AIBN 1.00. The experimentally determined quantity $k_{\mathrm{o}}$, defined by Equation (1), has been used to calculate termination rate coefficient, $k_{\mathrm{t}}$, according to Equation (2). Number-average degree of polymerization, $D P_{\mathrm{n}}$, has been estimated via Equation (5).

\begin{tabular}{cccccc}
\hline vol. \% STY & $\begin{array}{c}c_{\text {STY }} \\
\left(\mathrm{mol} \cdot \mathrm{L}^{-1}\right)\end{array}$ & $\begin{array}{c}c_{\text {AIBN }} \\
\left(\mathrm{mol} \cdot \mathrm{L}^{-1}\right)\end{array}$ & $\begin{array}{c}k_{\mathrm{o}} \\
\left(\mathrm{s}^{-1}\right)\end{array}$ & $\begin{array}{c}k_{\mathrm{t}} \\
\left(\mathrm{L} \cdot \mathrm{mol}^{-1} \cdot \mathrm{s}^{-1}\right)\end{array}$ & \\
\hline $100^{\mathrm{a}}$ & 8.433 & $5.58 \times 10^{-2}$ & $9.25 \times 10^{-6}$ & $5.65 \times 10^{7}$ & $8.00 \times 10^{2}$ \\
$100^{\mathrm{a}}$ & 8.433 & $5.59 \times 10^{-2}$ & $8.49 \times 10^{-6}$ & $6.72 \times 10^{7}$ & $7.35 \times 10^{2}$ \\
80 & 6.746 & $5.54 \times 10^{-2}$ & $7.27 \times 10^{-6}$ & $9.09 \times 10^{7}$ & $5.12 \times 10^{2}$ \\
80 & 6.746 & $5.59 \times 10^{-2}$ & $8.11 \times 10^{-6}$ & $7.37 \times 10^{7}$ & $5.65 \times 10^{2}$ \\
80 & 6.746 & $5.52 \times 10^{-2}$ & $8.15 \times 10^{-6}$ & $7.19 \times 10^{7}$ & $5.75 \times 10^{2}$ \\
80 & 6.746 & $5.52 \times 10^{-2}$ & $8.58 \times 10^{-6}$ & $6.49 \times 10^{7}$ & $6.05 \times 10^{2}$ \\
60 & 5.060 & $5.47 \times 10^{-2}$ & $8.53 \times 10^{-6}$ & $6.52 \times 10^{7}$ & $4.57 \times 10^{2}$ \\
60 & 5.060 & $5.60 \times 10^{-2}$ & $8.49 \times 10^{-6}$ & $6.72 \times 10^{7}$ & $4.45 \times 10^{2}$ \\
40 & 3.373 & $5.56 \times 10^{-2}$ & $8.22 \times 10^{-6}$ & $7.12 \times 10^{7}$ & $2.91 \times 10^{2}$ \\
40 & 3.373 & $5.59 \times 10^{-2}$ & $8.40 \times 10^{-6}$ & $6.85 \times 10^{7}$ & $2.96 \times 10^{2}$ \\
40 & 3.373 & $5.59 \times 10^{-2}$ & $7.90 \times 10^{-6}$ & $7.75 \times 10^{7}$ & $2.78 \times 10^{2}$ \\
20 & 1.687 & $5.49 \times 10^{-2}$ & $7.74 \times 10^{-6}$ & $7.93 \times 10^{7}$ & $1.40 \times 10^{2}$
\end{tabular}

${ }^{a}$ Result also included in Table 2 (i.e., not a separate experiment from that listed there). 
Table 4. Pre-exponential factor, $A$, and activation energy, $E_{\mathrm{a}}$, from Arrhenius fitting of data sets for termination rate coefficient, $k_{\mathrm{t}}$, from bulk polymerization of methyl methacrylate (MMA) and styrene (STY).

\begin{tabular}{|c|c|c|c|c|}
\hline Monomer & wt. \% AIBN & $\begin{array}{l}\text { Number of } \\
\text { data points }\end{array}$ & $\begin{array}{l}\quad A \\
\left(\mathrm{~L} \cdot \mathrm{mol}^{-1} \cdot \mathrm{s}^{-1}\right)\end{array}$ & $\begin{array}{c}\quad E_{\mathrm{a}} \\
\left(\mathrm{kJ} \cdot \mathrm{mol}^{-1}\right)\end{array}$ \\
\hline MMA & 0.01 & 15 & $1.358 \times 10^{8}$ & 4.85 \\
\hline MMA & 0.10 & 11 & $6.846 \times 10^{8}$ & 9.12 \\
\hline MMA & 1.00 & 12 & $2.200 \times 10^{8}$ & 6.25 \\
\hline MMA & all & $39^{\mathrm{a}}$ & $1.984 \times 10^{8}$ & 5.89 \\
\hline STY & 0.01 & $11^{\mathrm{b}}$ & $2.064 \times 10^{10}$ & 15.71 \\
\hline STY & 1.00 & 11 & $3.137 \times 10^{10}$ & 16.80 \\
\hline STY & all & $26^{c}$ & $1.341 \times 10^{10}$ & 14.34 \\
\hline \multicolumn{5}{|c|}{$\begin{array}{l}\text { a Includes also an experiment from using } 0.30 \mathrm{wt} \text {. \% AIBN (see Table } 1) \text {. } \\
{ }^{\mathrm{b}} \text { Excludes an outlier point }\left(80{ }^{\circ} \mathrm{C}, k_{\mathrm{t}}=4.03 \times 10^{7} \mathrm{~L} \cdot \mathrm{mol}^{-1} \cdot \mathrm{s}^{-1}-\text { see Table } 2\right) \text {. }\end{array}$} \\
\hline
\end{tabular}


Table 5. Activation energies used in Equation (15) to calculate $E_{\mathrm{a}}\left(k_{\mathrm{t}}\right)$ values of Figure 6.

\begin{tabular}{|c|c|c|c|c|}
\hline Quantity & $\begin{array}{c}E_{\mathrm{a}} \text { for } \mathrm{MMA} \\
\left(\mathrm{kJ} \cdot \mathrm{mol}^{-1}\right)\end{array}$ & $\begin{array}{c}\text { Ref. for MMA } \\
\text { value }^{\text {a }}\end{array}$ & $\begin{array}{c}E_{\mathrm{a}} \text { for STY } \\
\left(\mathrm{kJ} \cdot \mathrm{mol}^{-1}\right)\end{array}$ & $\begin{array}{c}\text { Ref. for STY } \\
\text { value }^{\text {a }}\end{array}$ \\
\hline$k_{\mathrm{t}}^{1,1}$ & 9.0 & [18] & 10.9 & {$[64]$} \\
\hline$f k_{\mathrm{d}}^{\mathrm{b}}$ & 123.5 & Equation (4a) [28] & 123.5 & Equation (4b) [28] \\
\hline$k_{\mathrm{p}}$ & 22.36 & Equation (3a) [26] & 32.51 & Equation (3b) [27] \\
\hline$c_{\mathrm{M}}^{\mathrm{c}}$ & -1.226 & Equation (7a) [38] & -1.005 & Equation (7b) [39] \\
\hline \multicolumn{5}{|c|}{ Equation refers to this work. } \\
\hline
\end{tabular}




\section{Figure Captions}

Figure 1. Results from 4 bulk polymerizations of methyl methacrylate at $70{ }^{\circ} \mathrm{C}$, where $x$ is fractional conversion, $t$ is time, and AIBN amount is as indicated. Points: experimental results (note that the two experiments with $1.0 \%$ AIBN were not strictly duplicates, as discussed in the text); lines: best fits to each set of results. The slope of each line is the rate parameter $k_{\mathrm{o}}$, defined by Equation (1) and reported in Tables 1-3 (Table 1 in the case of these particular results).

Figure 2. Log-log plot of termination rate coefficient, $k_{\mathrm{t}}$, versus concentration of 2,2'azoisobutyronitrile, $c_{\mathrm{AIBN}}$, for bulk polymerization of methyl methacrylate (MMA; lower results) and styrene (STY; upper results) at $70{ }^{\circ} \mathrm{C}$. Points: experimental values; lines: linear best fits, with slopes as displayed.

Figure 3. Log-log plot of termination rate coefficient, $k_{\mathrm{t}}$, versus concentration of styrene, $c_{\mathrm{STY}}$, for polymerization in ethyl benzene at $50{ }^{\circ} \mathrm{C}$ with 1.00 wt. $\%$ AIBN. Points: experimental values; line: linear best fit, with slope as displayed.

Figure 4. Arrhenius plot of termination rate coefficient, $k_{\mathrm{t}}$, versus inverse (absolute) temperature, $T^{-1}$, for bulk polymerization of (top to bottom, as indicated) styrene with 1.00 wt. $\%$ AIBN and with 0.01 wt. \% AIBN, and methyl methacrylate with 1.00 wt. \% AIBN and with 0.01 wt. \% AIBN. Points: experimental values; lines: Arrhenius fits (see Table 4).

Figure 5. Arrhenius plot of termination rate coefficient, $k_{\mathrm{t}}$, versus inverse (absolute) temperature, $T^{-1}$, for bulk polymerization of styrene and methyl methacrylate (as indicated) 
with all wt. \% AIBN. Points: experimental values; lines: Arrhenius fits (see Table 4 and Equations (14a) and (14b)).

Figure 6. Predicted activation energy of the overall termination rate coefficient, $E_{\mathrm{a}}\left(k_{\mathrm{t}}\right)$, for bulk methyl methacrylate (MMA) and styrene (STY) as a function of $\alpha$, the strength of the chain-length dependence of termination. Values are calculated with Equation (15) using the parameter values given in Table 5 .

Figure 7. Arrhenius plot of termination rate coefficient, $k_{\mathrm{t}}$, versus inverse (absolute) temperature, $T^{-1}$, for bulk polymerization of methyl methacrylate. Points: values from the Polymer Handbook; ${ }^{[65]}$ lines: Arrhenius fits for points and for all values of this work (Equation (14a), as also shown in Figure 5).

Figure 8. Arrhenius plot of termination rate coefficient, $k_{\mathrm{t}}$, versus inverse (absolute) temperature, $T^{-1}$, for bulk polymerization of methyl methacrylate. Line: Arrhenius fit for all values of this work (Equation (14a), as also shown in Figure 5); points: values from Mahabadi and O'Driscoll, ${ }^{[66]}$ Fukuda et al., ${ }^{[30]}$ Meyerhoff and Sack-Kouloumbris, ${ }^{[67]}$ Buback and Kowollik, ${ }^{[68]}$ Stickler $^{[59]}$ (as evaluated by Smith ${ }^{[69]}$ ), Olaj and Vana, ${ }^{[43]}$ and Matheson et al. ${ }^{[70]}$ (rotating sector data reevaluated here using Equation (3a)).

Figure 9. Arrhenius plot of termination rate coefficient, $k_{\mathrm{t}}$, versus inverse (absolute) temperature, $T^{-1}$, for bulk polymerization of styrene. Line: Arrhenius fit for all values of this work (Equation (14b), as also shown in Figure 5); points: values from Mahabadi and O'Driscoll, ${ }^{[66]}$ Fukuda et al., ${ }^{[30]}$ Yamada et al., ${ }^{[71]}$ Buback and Kuchta, ${ }^{[72]}$ Olaj and Vana, ${ }^{[49]}$ and Matheson et al. ${ }^{[39]}$ (rotating sector data reevaluated here using Equation (3b)). 
Figure 1

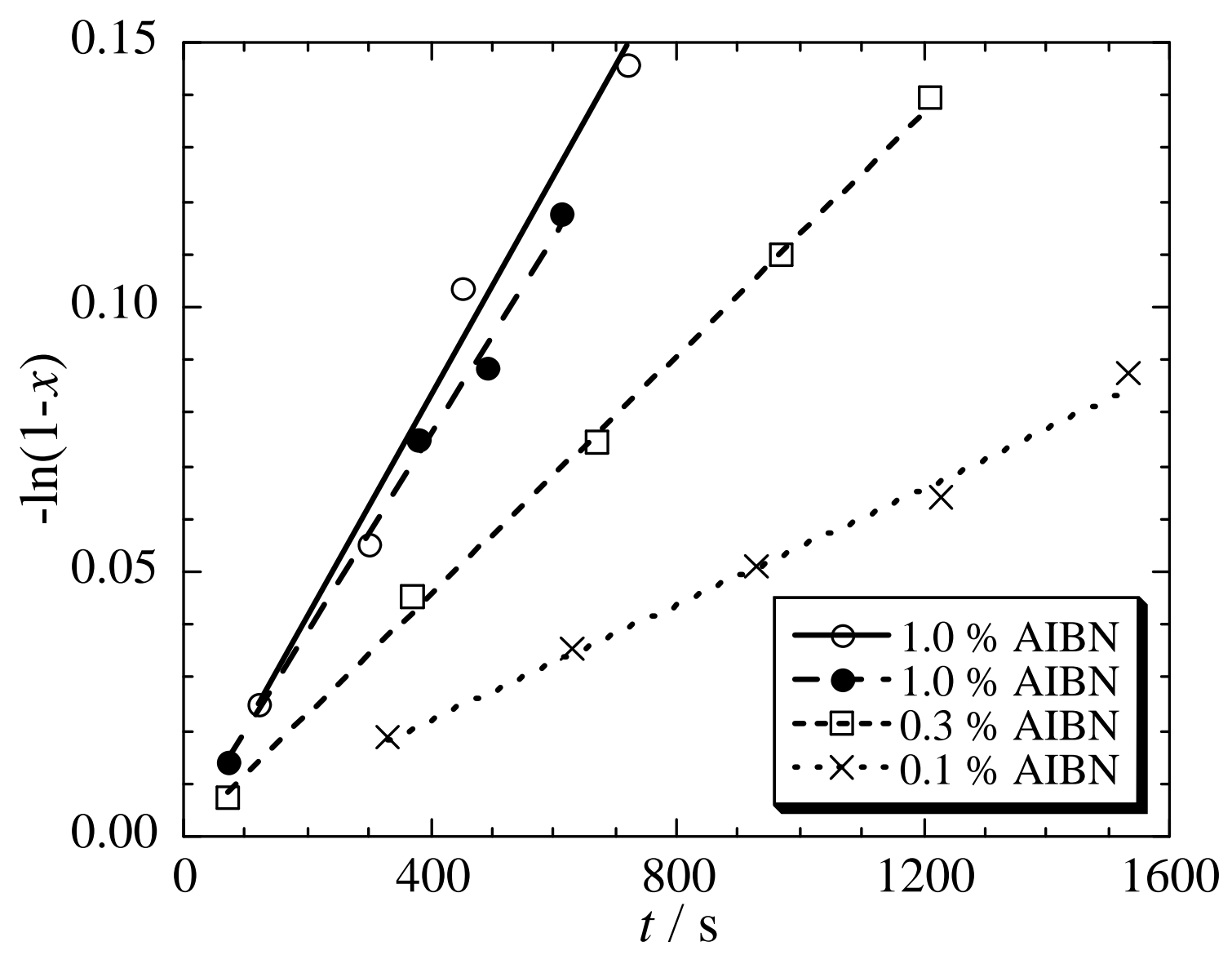


Figure 2

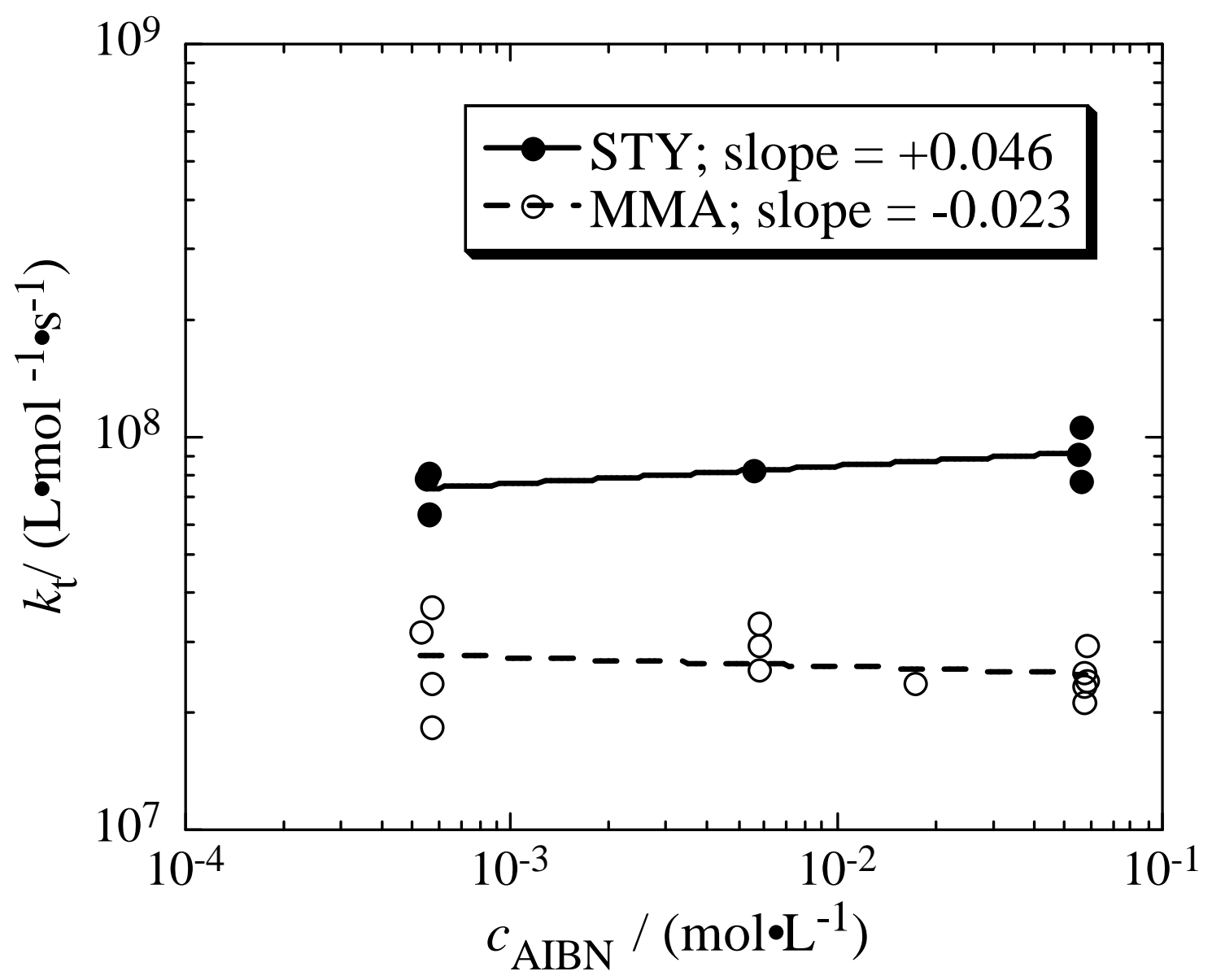


Figure 3

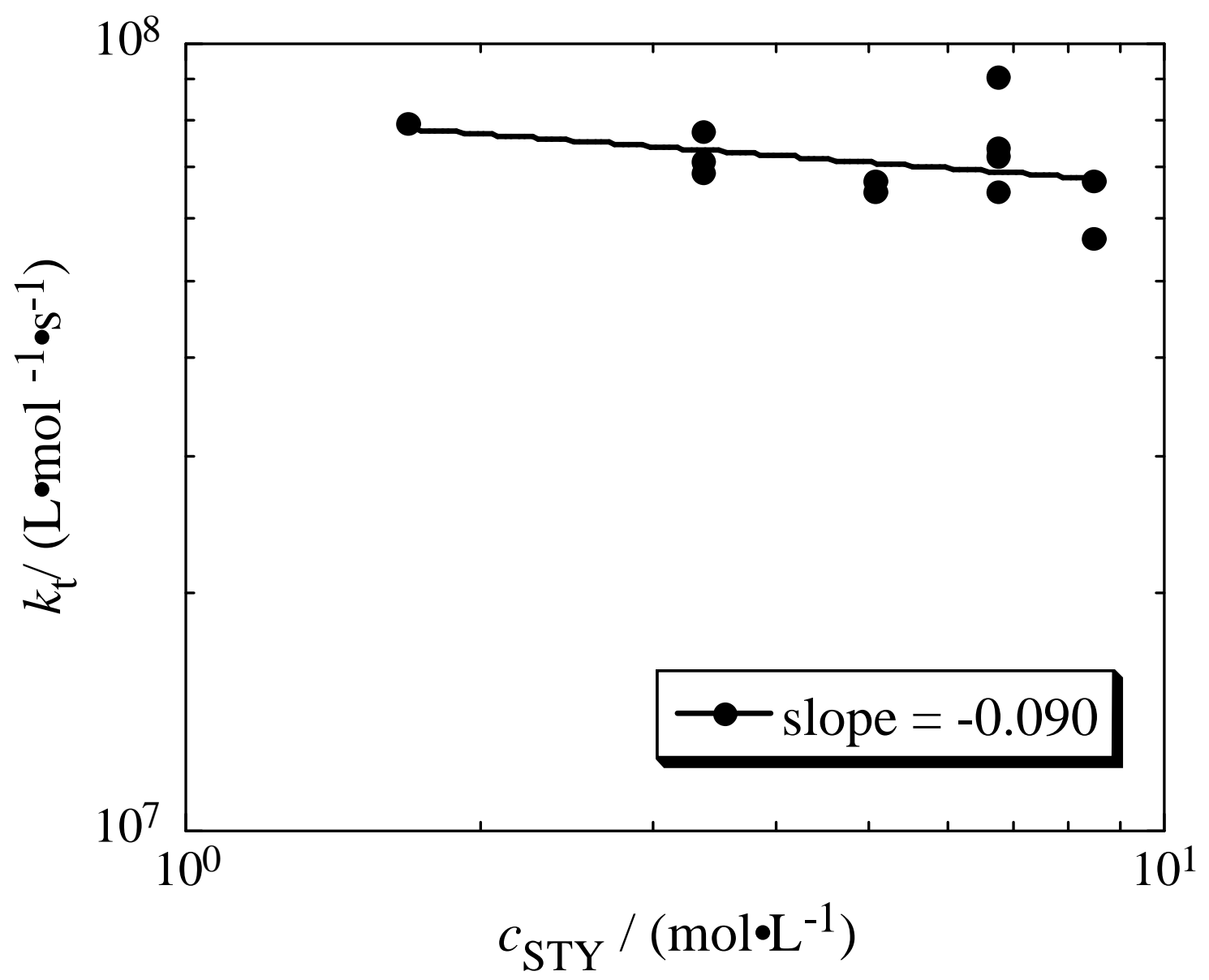


Figure 4

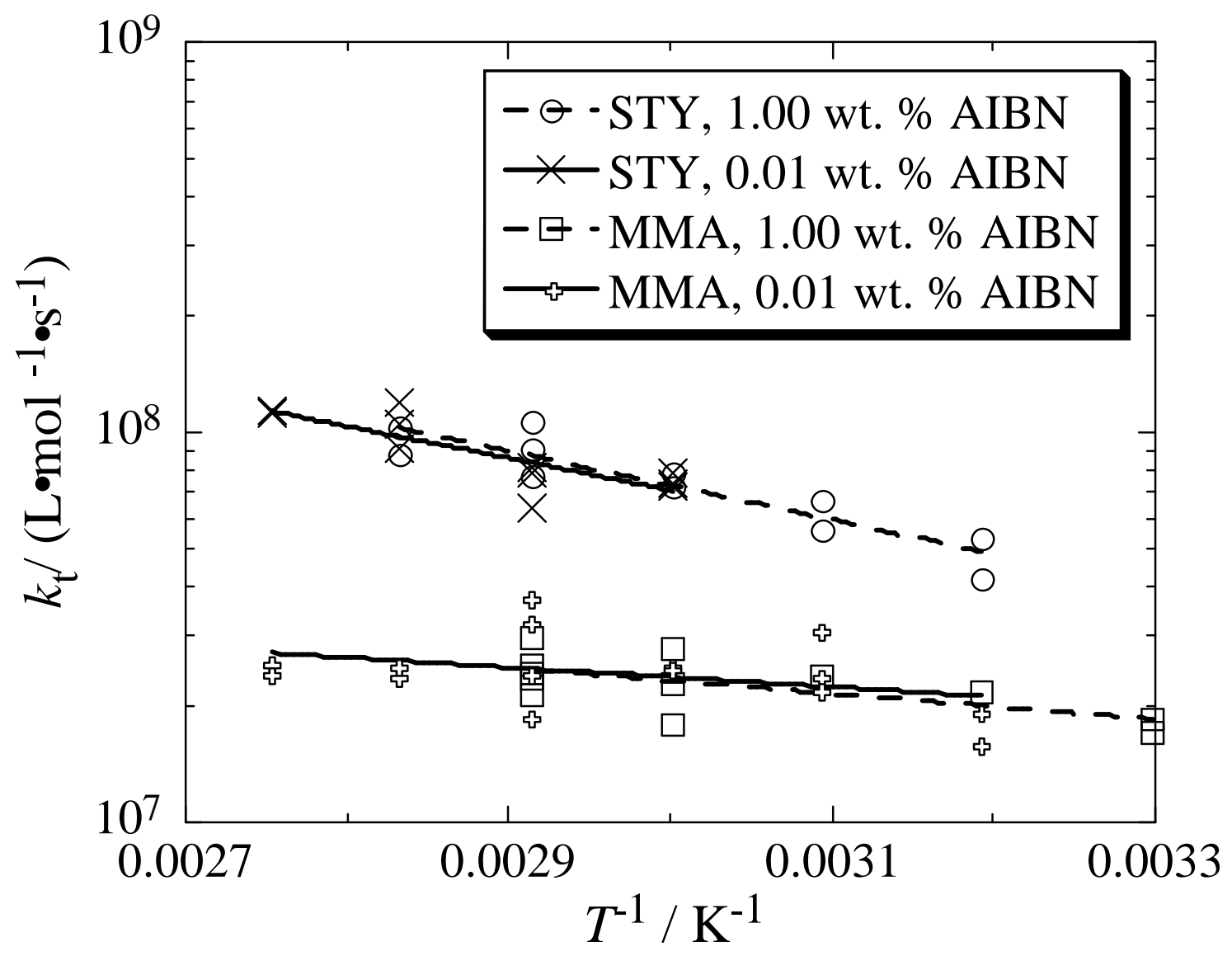


Figure 5

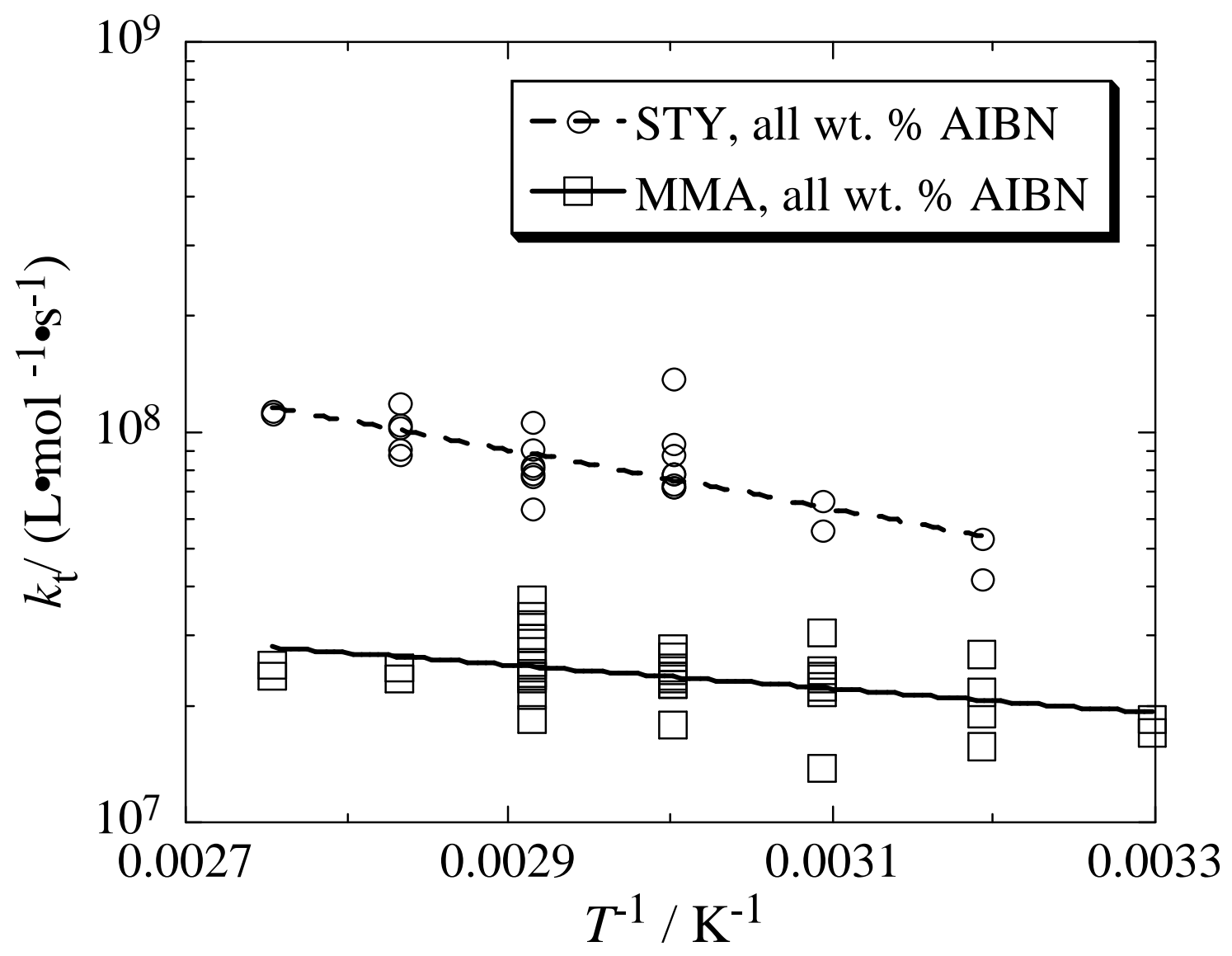


Figure 6

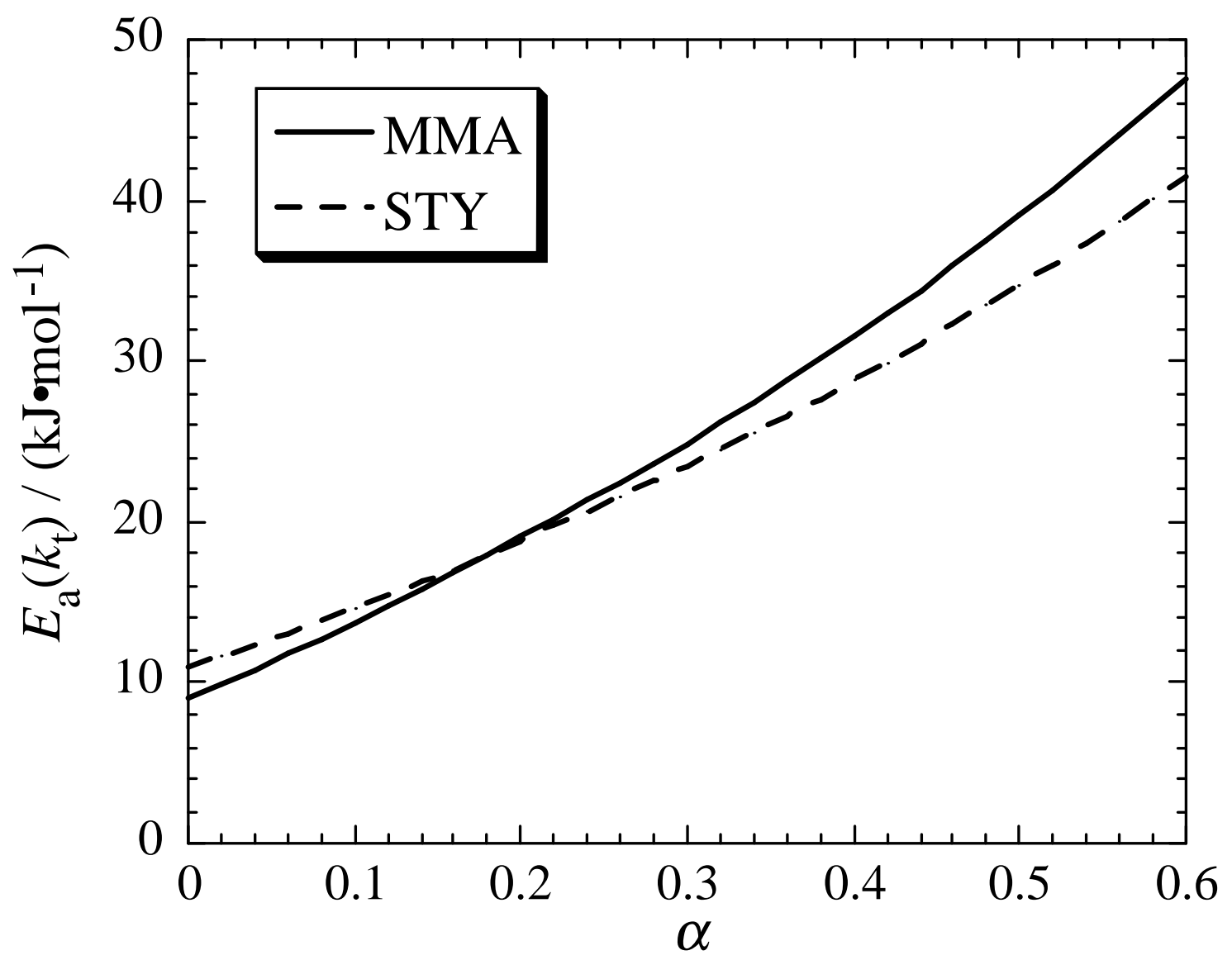


Figure 7

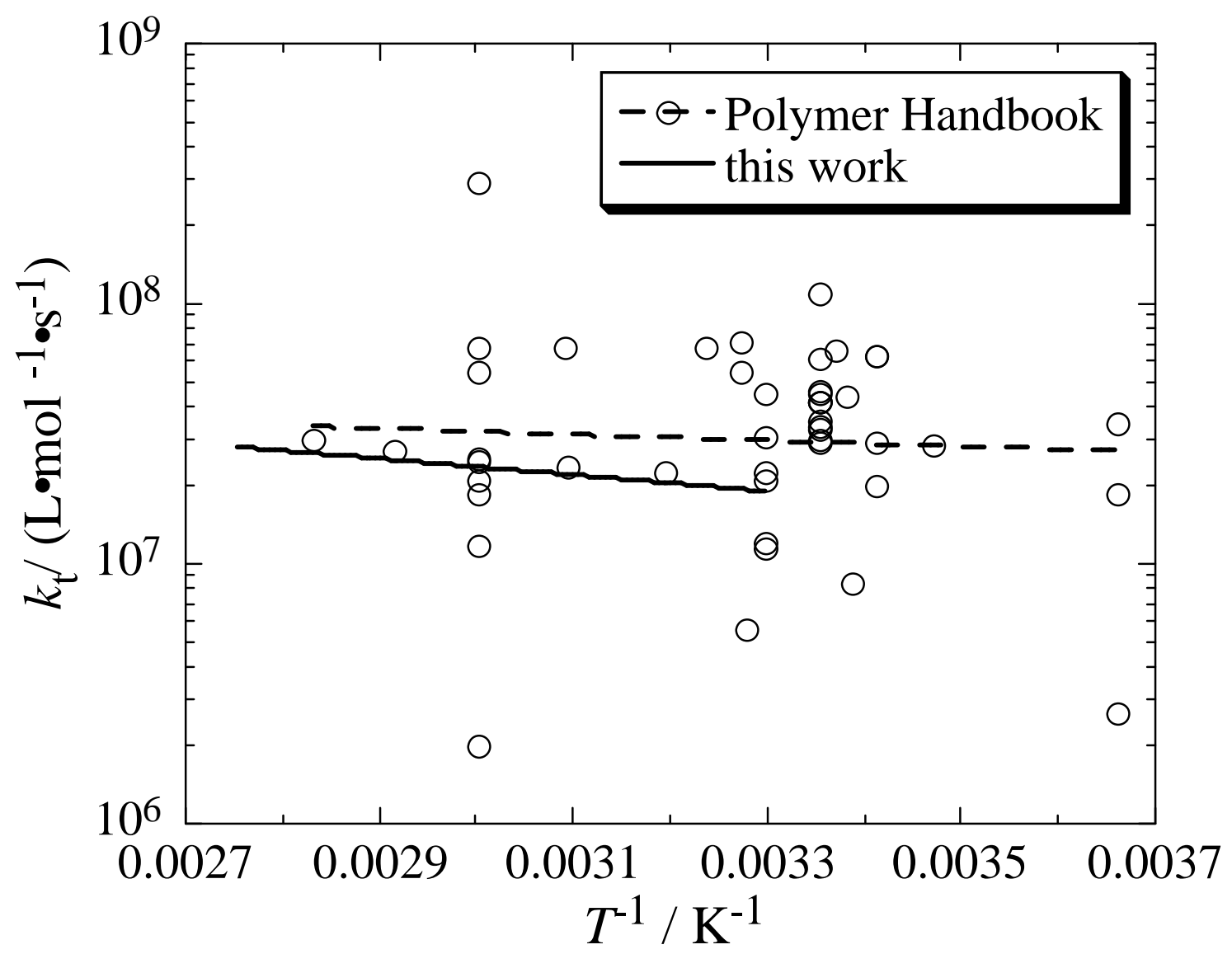


Figure 8

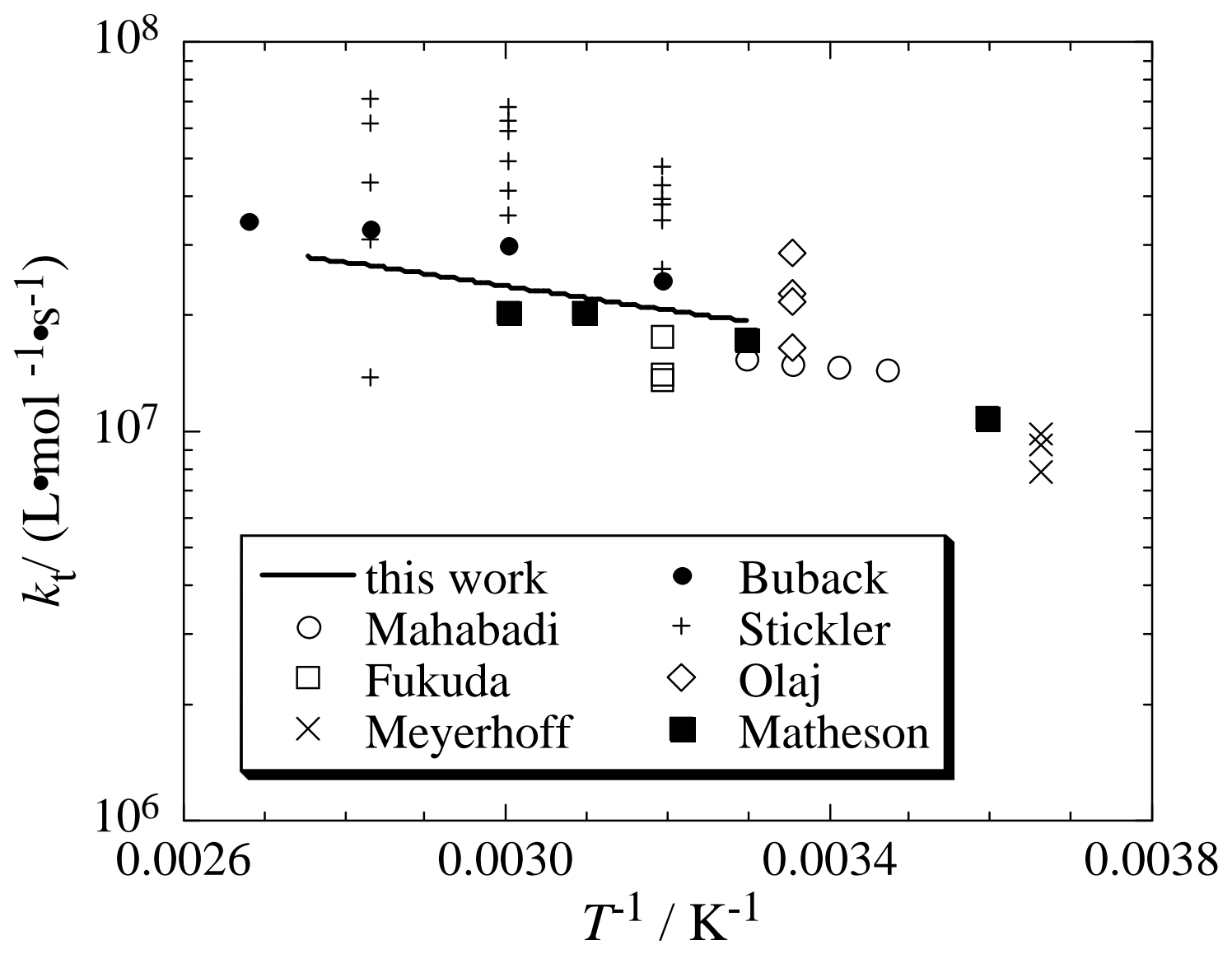


Figure 9

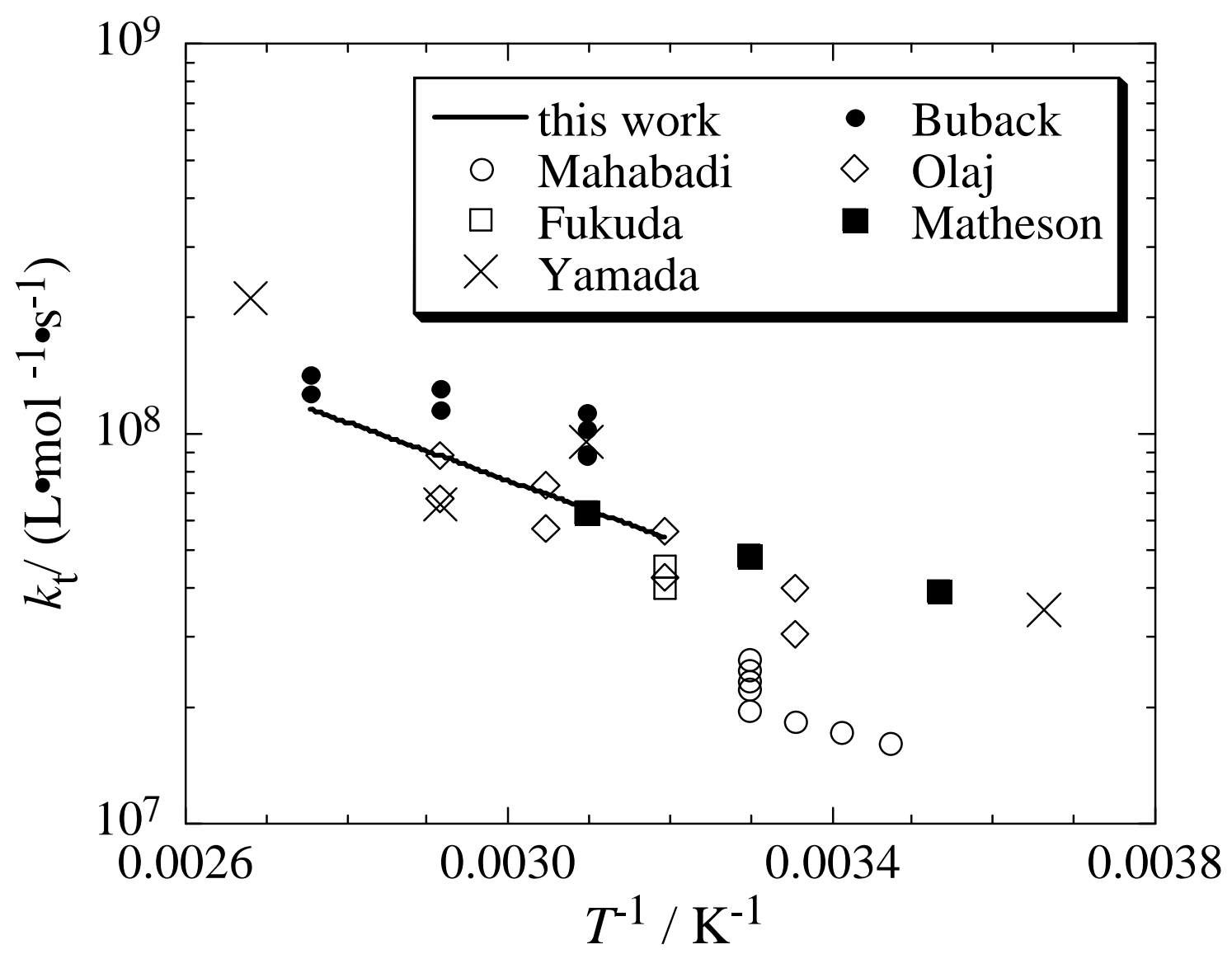




\section{References}

[1] G. Moad, E. Rizzardo, S. H. Thang, Acc. Chem. Res. 2008, 41, 1133.

[2] K. Matyjaszewski, N. V. Tsarevsky, Nature Chem. 2009, 1, 276.

[3] "Handbook of RAFT Polymerization", 1st edition, C. Barner-Kowollik, Eds., WileyVCH, Weinheim 2008.

[4] H. Fischer, Chem. Rev. 2001, 101, 3581.

[5] A. Goto, T. Fukuda, Prog. Polym. Sci. 2004, 29, 329.

[6] C. Barner-Kowollik, G. T. Russell, Prog. Polym. Sci. 2009, 34, 1211.

[7] M. Buback, M. Egorov, T. Junkers, E. Panchenko, Macromol. Rapid Commun. 2004, 25, 1004.

[8] M. Buback, M. Egorov, T. Junkers, E. Panchenko, Macromol. Chem. Phys. 2005, 206, 333.

[9] M. Buback, E. Müller, G. T. Russell, J. Phys. Chem. A 2006, 110, 3222.

[10] M. Buback, T. Junkers, M. Müller, Polymer 2009, 50, 3111.

[11] J. Barth, M. Buback, P. Hesse, T. Sergeeva, Macromolecules 2009, 42, 481.

[12] M. Buback, T. Junkers, P. Vana, Macromol. Rapid Commun. 2005, 26, 796.

[13] T. Junkers, A. Theis, M. Buback, T. P. Davis, M. H. Stenzel, P. Vana, C. BarnerKowollik, Macromolecules 2005, 38, 9497.

[14] M. Buback, P. Hesse, T. Junkers, T. Theis, P. Vana, Aust. J. Chem. 2007, 60, 779.

[15] P. Vana, T. P. Davis, C. Barner-Kowollik, Macromol. Rapid Commun. 2002, 23, 952.

[16] G. Johnston-Hall, M. J. Monteiro, J. Polym. Sci., Polym. Chem. Ed. 2008, 46, 3155.

[17] G. Johnston-Hall, A. Theis, M. J. Monteiro, T. P. Davis, M. H. Stenzel, C. BarnerKowollik, Macromol. Chem. Phys. 2005, 206, 2047.

[18] J. Barth, M. Buback, Macromol. Rapid Commun. 2009, 30, 1805.

[19] J. Barth, M. Buback, G. Schmidt-Naake, I. Woecht, Polymer 2009, $50,5708$.

[20] G. Johnston-Hall, M. J. Monteiro, Macromolecules 2008, 41, 727.

[21] G. B. Smith, G. T. Russell, J. P. A. Heuts, Macromol. Theory Simul. 2003, 12, 299.

[22] C. Barner-Kowollik, M. Buback, M. Egorov, T. Fukuda, A. Goto, O. F. Olaj, G. T. Russell, P. Vana, B. Yamada, P. B. Zetterlund, Prog. Polym. Sci. 2005, 30, 605.

[23] G. T. Russell, Aust. J. Chem. 2002, 55, 399.

[24] G. B. Smith, G. T. Russell, Macromol. Symp. 2007, $248,1$.

[25] M. Buback, M. Egorov, R. G. Gilbert, V. Kaminsky, O. F. Olaj, G. T. Russell, P. Vana, G. Zifferer, Macromol. Chem. Phys. 2002, 203, 2570.

[26] S. Beuermann, M. Buback, T. P. Davis, R. G. Gilbert, R. A. Hutchinson, O. F. Olaj, G. T. Russell, J. Schweer, A. M. van Herk, Macromol. Chem. Phys. 1997, 198, 1545.

[27] M. Buback, R. G. Gilbert, R. A. Hutchinson, B. Klumperman, F.-D. Kuchta, B. G. Manders, K. F. O'Driscoll, G. T. Russell, J. Schweer, Macromol. Chem. Phys. 1995, 196, 3267.

[28] G. T. Russell, Macromol. Theory Simul. 1995, 4, 549.

[29] K. C. Berger, Makromol. Chem. 1975, 176, 3575.

[30] T. Fukuda, Y.-D. Ma, H. Inagaki, Macromolecules 1985, 18, 17.

[31] M. Buback, B. Huckestein, F.-D. Kuchta, G. T. Russell, E. Schmid, Macromol. Chem. Phys. 1994, 195, 2117.

[32] M. Buback, C. Hinton, Z. Phys. Chem. (Munich) 1997, 199, 229. 
[33] C. A. Barson, "Chain Transfer", in vol. 3 of: Comprehensive Polymer Science: The Synthesis, Characterization, Reactions and Applications of Polymers, G. A. Allen, J. C. Bevington, Eds., Pergamon, Oxford 1989, p. 171.

[34] M. Stickler, G. Meyerhoff, Makromol. Chem. 1978, 179, 2729.

[35] A. V. Tobolsky, J. Offenbach, J. Polym. Sci. 1955, XVI, 311.

[36] M. Buback, F. Günzler, G. T. Russell, P. Vana, Macromolecules 2009, 42, 652.

[37] G. Moad, D. H. Solomon, "The Chemistry of Free Radical Polymerization", 1st edition, Pergamon, Oxford 1995.

[38] G. C. Eastmond, Makromol. Chem., Macromol. Symp. 1987, 10/11, 71.

[39] M. S. Matheson, E. E. Auer, E. B. Bevilacqua, E. J. Hart, J. Am. Chem. Soc. 1951, 73, 1700.

[40] J. P. A. Heuts, G. T. Russell, G. B. Smith, A. M. van Herk, Macromol. Symp. 2007, $248,12$.

[41] M. C. Griffiths, J. Strauch, M. J. Monteiro, R. G. Gilbert, Macromolecules 1998, 31, 7835.

[42] M. Buback, M. Egorov, A. Feldermann, Macromolecules 2004, 37, 1768.

[43] O. F. Olaj, P. Vana, Macromol. Rapid Commun. 1998, 19, 533.

[44] O. F. Olaj, P. Vana, A. Kornherr, G. Zifferer, Macromol. Chem. Phys. 1999, 200, 2031.

[45] H. K. Mahabadi, Macromolecules 1985, 18, 1319.

[46] H. K. Mahabadi, Macromolecules 1991, 24, 606.

[47] B. Friedman, B. O'Shaughnessy, Macromolecules 1993, 26, 5726.

[48] M. C. Piton, R. G. Gilbert, B. E. Chapman, P. W. Kuchel, Macromolecules 1993, 26, 4472.

[49] O. F. Olaj, P. Vana, Macromol. Rapid Commun. 1998, 19, 433.

[50] G. B. Smith, J. P. A. Heuts, G. T. Russell, Macromol. Symp. 2005, 226, 133.

[51] G. T. Russell, Macromol. Theory Simul. 1995, 4, 519.

[52] P. A. Clay, R. G. Gilbert, G. T. Russell, Macromolecules 1997, 30, 1935.

[53] N. García, P. Tiemblo, J. Guzmán, Macromolecules 2007, 40, 4802.

[54] J. P. A. Heuts, G. T. Russell, Eur. Polym. J. 2006, 42, 3.

[55] G. B. Smith, G. T. Russell, M. Yin, J. P. A. Heuts, Eur. Polym. J. 2005, 41, 225.

[56] O. F. Olaj, P. Vana, M. Zoder, A. Kornherr, G. Zifferer, Macromol. Rapid Commun. 2000, 21, 913.

[57] O. F. Olaj, M. Zoder, P. Vana, A. Kornherr, I. Schnöll-Bitai, G. Zifferer, Macromolecules 2005, 38, 1944.

[58] H. K. Mahabadi, K. F. O’Driscoll, Macromolecules 1977, 10, 55.

[59] M. Stickler, Makromol. Chem. 1986, 187, 1765.

[60] O. F. Olaj, M. Zoder, P. Vana, Macromolecules 2001, 34, 441.

[61] O. F. Olaj, P. Vana, J. Polym. Sci., Polym. Chem. Ed. 2000, 38, 697.

[62] M. Stickler, D. Panke, W. Wunderlich, Makromol. Chem. 1987, 188, 2651.

[63] J. P. A. Heuts, G. E. Roberts, J. D. Biasutti, Aust. J. Chem. 2002, 55, 381.

[64] S. Pickup, F. D. Blum, Macromolecules 1989, 22, 3961.

[65] K. C. Berger, G. Meyerhoff, "Propagation and Termination Constants in Free Radical Polymerization", in: Polymer Handbook, 3rd edition, A. Brandrup, E. H. Immergut, Eds., Wiley-Interscience, New York 1989, p. II/67.

[66] H. K. Mahabadi, K. F. O'Driscoll, J. Macromol. Sci., Chem. 1977, A11, 967.

[67] R. Sack-Kouloumbris, G. Meyerhoff, Makromol. Chem. 1989, 190, 1133. 
[68] M. Buback, C. Kowollik, Macromolecules 1998, 31, 3211.

[69] G. B. Smith, Ph.D. Thesis, The University of Canterbury (2007).

[70] M. S. Matheson, E. E. Auer, E. B. Bevilacqua, E. J. Hart, J. Am. Chem. Soc. 1949, 71, 497.

[71] B. Yamada, M. Kageoka, T. Otsu, Polym. Bull. (Berlin) 1992, 29, 385.

[72] M. Buback, F.-D. Kuchta, Macromol. Chem. Phys. 1997, 198, 1455.

[73] H. Fischer, H. Paul, Acc. Chem. Res. 1987, 20, 200.

[74] R. A. Waggoner, F. Blum, J. M. D. MacElroy, Macromolecules 1993, 26, 6841.

[75] G. T. Russell, Macromol. Theory Simul. 1995, 4, 497.

[76] M. Buback, P. Hesse, T. Junkers, T. Theis, P. Vana, Aust. J. Chem. 2007, 60, 779.

[77] J. M. Asua, S. Beuermann, M. Buback, P. Castignolles, B. Charleux, R. G. Gilbert, R. A. Hutchinson, J. R. Leiza, A. N. Nikitin, J.-P. Vairon, A. M. van Herk, Macromol. Chem. Phys. 2004, 205, 2151. 